\title{
Bisboronic Acids for Selective, Physiologically Relevant Direct Glucose Sensing with Surface-Enhanced Raman Spectroscopy
}

Bhavya Sharma $^{\dagger}$, Pradeep Bugga ${ }^{\ddagger}$, Lindsey R. Madison ${ }^{\%}$, Anne-Isabelle Henry ${ }^{\ddagger}$, Martin G. Blaber $^{\S}$, Nathan G. Greeneltch ${ }^{\#}$, Naihao Chiang ${ }^{\star}$, Milan Mrksich ${ }^{\ddagger}$, George C. Schatz ${ }^{\star}$, Richard P. Van Duyne ${ }^{+*}$

†Department of Chemistry, Northwestern University, 2145 Sheridan Rd., Evanston, IL 60208

$\dagger$ Department of Chemistry, University of Tennessee, 1420 Circle Dr., Knoxville, TN 37931

Corresponding author: vanduyne@northwestern.edu

\section{SUPPORTING INFORMATION}

\section{Materials and Methods}

Reactions were performed in flame-dried glassware under a nitrogen atmosphere unless otherwise specified using solvents purchased in anhydrous Sure/Seal ${ }^{\mathrm{TM}}$ bottles from SigmaAldrich. Additionally, dry, deoxygenated dichloromethane passed over a column of activated alumina was used. Reagents were purchased from Sigma-Aldrich without further purification. Thin-layer chromatography (TLC) was performed using EMD/Merck KGaA plates precoated with silica gel 60 F254 and visualized by UV fluorescence quenching. Preparative TLC was performed on $20 \mathrm{~cm}$ x $20 \mathrm{~cm}$ silica gel plates $(1.00 \mathrm{~mm}$, thick, Analtech). Silica gel $(40-60 \mu \mathrm{m}$ particle size) from Agela Technologies was used for flash chromatography. Preparative reversephase HPLC was performed on a Waters 600 HPLC system with a Nucelodur ${ }^{\circledR}$ C18 column ( $250 \mathrm{~mm} \times 21 \mathrm{~mm}, 5 \mu \mathrm{m}$ particle size, $8.0 \mathrm{~mL} / \mathrm{min}$ flow rate) employing a variable gradient of acetonitrile and water. ${ }^{1} \mathrm{H}$ and ${ }^{13} \mathrm{C}$ NMR spectra were recorded on a Varian Inova 500, Agilent DD2 600, and Bruker Avance III 500 at $500 \mathrm{MHz}$ and $125 \mathrm{MHz}$, respectively. Data for ${ }^{1} \mathrm{H}$ spectra is reported in terms of chemical shift relative to $\mathrm{CDCl}_{3}(\delta 7.26 \mathrm{ppm})$ or $\mathrm{CD}_{3} \mathrm{OD}(\delta 3.31$ ppm) while that for ${ }^{13} \mathrm{C} \mathrm{NMR}$ is reported relative to $\mathrm{CDCl} 3(\delta 77.2 \mathrm{ppm})$ or $\mathrm{CD}_{3} \mathrm{OD}(\delta 49.0$ ppm). HRMS was acquired on an Agilent 6210A LC-TOF mass spectrometer using electrospray ionization (ESI). UV-Vis absorption spectra were acquired using a Beckman Coulter DU-800 spectrophotometer in a $10 \mathrm{~mm}$ UV silica cell.

\section{Experimental Procedures}

\subsection{Synthetic Procedures}

The procedure from Dalyl et al. ${ }^{1}$ was used to prepare cysteamine disulfide $\mathbf{1}$. Additionally, considering the propensity of the pyridyl disulfide group to disproportionate in light ${ }^{2}$, all pyridyl disulfide intermediates were stored in the dark. 


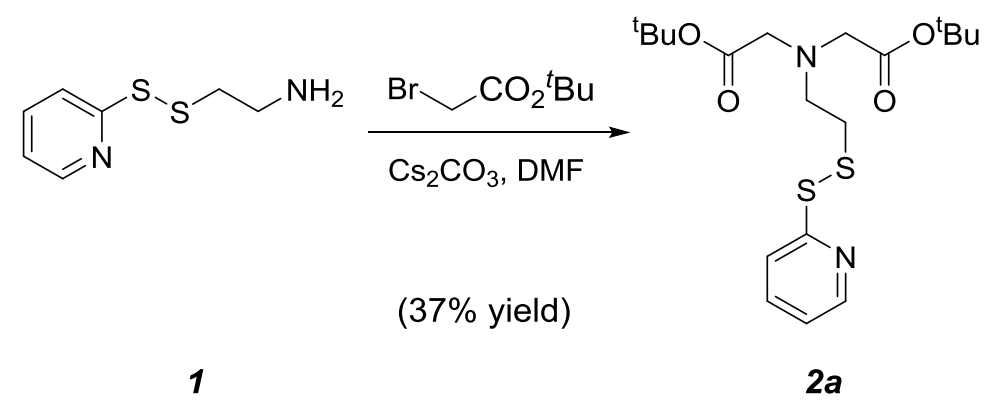

To a flask was added cysteamine disulfide (150 $\mathrm{mg}, 0.805 \mathrm{mmol})$, cesium carbonate $(1.77 \mathrm{mmol}, 577 \mathrm{mg})$, tert-butyl bromoacetate $(1.77 \mathrm{mmol}, 261 \mu \mathrm{L})$, and DMF $(8.1$ $\mathrm{mL})$. After amine 1 was consumed as measured by TLC, the reaction was diluted in added sat. $\mathrm{NaHCO}_{3}(25 \mathrm{~mL})$. After extracting with diethyl ether $(2 \times 25 \mathrm{~mL})$, the combined organics were washed with water $(25 \mathrm{~mL})$, dried with $\mathrm{MgSO}_{4}$, filtered, then concentrated under vacuum. Silica gel chromatography eluted with 6:1 hexanes / ethyl acetate yielded 2a as a faintly yellow oil (123 $\mathrm{mg}, 37 \%) ; R_{\mathrm{f}}=0.40$ (3:1 hexanes / ethyl acetate); ${ }^{1} \mathrm{H} \mathrm{NMR}\left(500 \mathrm{MHz}, \mathrm{CDCl}_{3}\right) \delta 8.45$ (ddd, $J=$ 4.9, 1.9, $1.0 \mathrm{~Hz}, 1 \mathrm{H}), 7.74(\mathrm{dt}, J=8.1,1.0 \mathrm{~Hz}, 1 \mathrm{H}), 7.63(\mathrm{ddd}, J=8.2,7.5,1.9 \mathrm{~Hz}, 1 \mathrm{H}), 7.07$ (ddd, $J=7.4,4.8,1.1 \mathrm{~Hz}, 1 \mathrm{H}), 3.44(\mathrm{~s}, 4 \mathrm{H}), 3.07(\mathrm{~d}, J=9.4 \mathrm{~Hz}, 1 \mathrm{H}), 3.06(\mathrm{~d}, J=8.0 \mathrm{~Hz}, 1 \mathrm{H})$, $2.94(\mathrm{~d}, J=8.1 \mathrm{~Hz}, 1 \mathrm{H}), 2.93(\mathrm{~d}, J=9.4 \mathrm{~Hz}, 1 \mathrm{H}), 1.43(\mathrm{~s}, 18 \mathrm{H}) ;{ }^{13} \mathrm{C} \mathrm{NMR}\left(125 \mathrm{MHz}, \mathrm{CDCl}_{3}\right) \delta$ 170.64, 160.6, 149.7, 137.1, 120.7, 119.8, 81.3, 56.3, 54.0, 37.5, 28.3; HRMS (ESI) $\mathrm{m} / z$ calc'd for $\mathrm{C}_{19} \mathrm{H}_{30} \mathrm{~N}_{2} \mathrm{O}_{4} \mathrm{~S}_{2}[\mathrm{M}+\mathrm{H}]^{+}:$415.1725, found 415.1728.

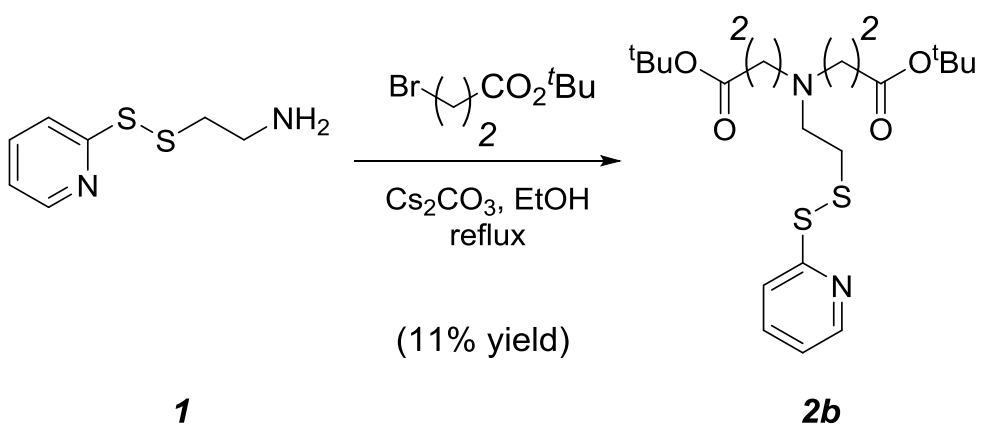

To a flask added cysteamine disulfide $(250 \mathrm{mg}, 1.34 \mathrm{mmol})$, cesium carbonate $(1.31 \mathrm{~g}$, $4.03 \mathrm{mmol})$, tert-butyl bromoacetate $(1.34 \mathrm{~mL}, 8.05 \mathrm{mmol})$, and EtOH $(13.4 \mathrm{~mL})$. After refluxing the reaction mixture overnight and observing that $\mathbf{1}$ was consumed by TLC analysis, the reaction was cooled then filtered over a cotton plug (in a Pasteur pipette). After concentrating down under vacuum, purification via preparative TLC (2:1 hexanes / ethyl acetate) yielded $\mathbf{2 b}$ as a faintly yellow oil $(63 \mathrm{mg}, 11 \%) ; R_{\mathrm{f}}=0.40$ (3:1 hexanes / ethyl acetate); ${ }^{1} \mathrm{H}$ NMR $(500 \mathrm{MHz}$, $\left.\mathrm{CDCl}_{3}\right) \delta 8.46(\mathrm{ddd}, J=4.8,1.8,0.9 \mathrm{~Hz}, 1 \mathrm{H}), 7.74(\mathrm{dt}, J=8.1,1.0 \mathrm{~Hz}, 1 \mathrm{H}), 7.65$ (ddd, $J=8.1$, 7.4, $1.9 \mathrm{~Hz}, 1 \mathrm{H}), 7.07$ (ddd, $J=7.3,4.8,1.1 \mathrm{~Hz}, 1 \mathrm{H}), 2.90(\mathrm{~d}, J=8.8 \mathrm{~Hz}, 1 \mathrm{H}), 2.89(\mathrm{~d}, J=7.7$ $\mathrm{Hz}, 1 \mathrm{H}), 2.78(\mathrm{~d}, J=7.7 \mathrm{~Hz}, 1 \mathrm{H}), 2.77(\mathrm{~d}, J=8.9 \mathrm{~Hz}, 1 \mathrm{H}), 2.74(\mathrm{t}, J=7.2 \mathrm{~Hz}, 4 \mathrm{H}), 2.34(\mathrm{t}, J=$ $7.3 \mathrm{~Hz}, 4 \mathrm{H}), 1.43(\mathrm{~s}, 18 \mathrm{H}) ;{ }^{13} \mathrm{C}$ NMR $\left(125 \mathrm{MHz}, \mathrm{CDCl}_{3}\right) \delta 172.0,160.6,149.8,137.1,120.7$, 119.8, 80.5, 53.1, 49.5, 37.2, 34.0, 28.3; HRMS (ESI) $\mathrm{m} / z$ calc'd for $\mathrm{C}_{21} \mathrm{H}_{35} \mathrm{~N}_{2} \mathrm{O}_{4} \mathrm{~S}_{2}[\mathrm{M}+\mathrm{H}]^{+}$: 443.2038, found 443.2042. 


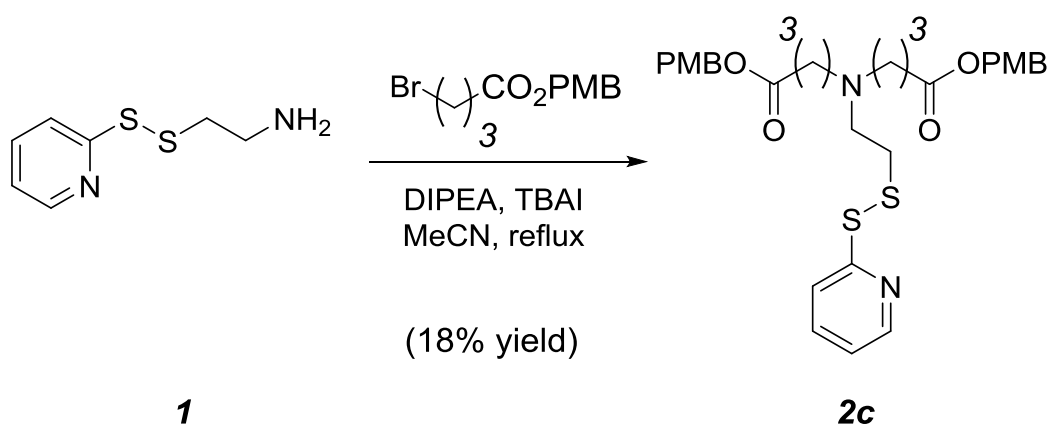

[Note: 4-methoxybenzyl 4-bromobutanoate was prepared according to a procedure from Sharma et $\left.a .^{3}{ }^{3}\right]$

To a flask was added cysteamine disulfide $(250 \mathrm{mg}, 1.34 \mathrm{mmol})$, tetrabutylammonium iodide $(50 \mathrm{mg}, 0.134 \mathrm{mmol}), \mathrm{N}, \mathrm{N}$-diisopropylethylamine $(1.57 \mathrm{~mL}, 8.99 \mathrm{mmol}), 4-$ methoxybenzyl 4-bromobutanoate $(1.31 \mathrm{~g}, 4.56 \mathrm{mmol})$ and acetonitrile $(13.4 \mathrm{~mL})$. After refluxing overnight and observing that $\mathbf{1}$ was consumed by TLC analysis, the reaction mixture was diluted in water $(20 \mathrm{~mL})$ and extracted with diethyl ether $(2 \times 25 \mathrm{~mL})$. Subsequently, the organic layer was washed with water $(2 \times 25 \mathrm{~mL})$, dried with $\mathrm{MgSO}_{4}$, filtered, then concentrated under vacuum. Purification via preparative TLC (2:1 hexanes / ethyl acetate) yielded 2c as a yellow oil (148 mg, 18\%); $R_{\mathrm{f}}=0.43\left(2: 1\right.$ hexanes / ethyl acetate); ${ }^{1} \mathrm{H}$ NMR $\left(500 \mathrm{MHz}, \mathrm{CDCl}_{3}\right)$ $\delta 8.44$ (ddd, $J=4.8,1.9,0.9 \mathrm{~Hz}, 1 \mathrm{H}), 7.70(\mathrm{dt}, J=8.1,1.1 \mathrm{~Hz}, 1 \mathrm{H}), 7.62$ (ddd, $J=8.1,7.4,1.8$ $\mathrm{Hz}, 1 \mathrm{H}), 7.28(\mathrm{~d}, J=8.7 \mathrm{~Hz}, 4 \mathrm{H}), 7.06(\mathrm{ddd}, J=7.4,4.8,1.1 \mathrm{~Hz}, 1 \mathrm{H}), 6.87(\mathrm{~d}, J=8.7 \mathrm{~Hz}, 4 \mathrm{H})$, $5.03(\mathrm{~s}, 4 \mathrm{H}), 3.80(\mathrm{~s}, 6 \mathrm{H}), 2.81(\mathrm{~d}, J=8.7 \mathrm{~Hz}, 1 \mathrm{H}), 2.80(\mathrm{~d}, J=7.5 \mathrm{~Hz}, 1 \mathrm{H}), 2.72(\mathrm{~d}, J=7.6 \mathrm{~Hz}$, $1 \mathrm{H}), 2.71(\mathrm{~d}, J=8.8 \mathrm{~Hz}, 1 \mathrm{H}), 2.40(\mathrm{t}, J=7.0 \mathrm{~Hz}, 4 \mathrm{H}), 2.33(\mathrm{t}, J=7.2 \mathrm{~Hz}, 4 \mathrm{H}), 1.70(\mathrm{p}, J=7.2$ $\mathrm{Hz}, 4 \mathrm{H}) ;{ }^{13} \mathrm{C}$ NMR $\left(500 \mathrm{MHz}, \mathrm{CDCl}_{3}\right) \delta 173.6,160.6,159.8,149.8,137.1,130.3,128.3,120.7$, 119.8, 114.1, 66.1, 55.4, 53.1, 37.2, 32.0, 22.7; HRMS (ESI) m/z calc'd for $\mathrm{C}_{31} \mathrm{H}_{38} \mathrm{~N}_{2} \mathrm{O}_{6} \mathrm{~S}_{2}$ $[\mathrm{M}+\mathrm{H}]^{+}: 599.2250$, found 599.2249

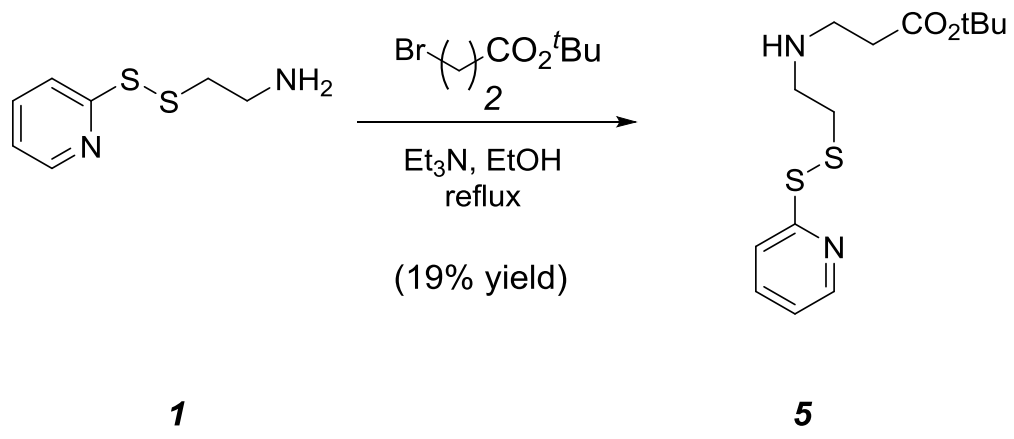

To a flask was added cysteamine disulfide (500 mg, $2.68 \mathrm{mmol})$, tert-butyl 3bromopropionate ( $537 \mu \mathrm{L}, 3.22 \mathrm{mmol})$, triethylamine ( $748 \mathrm{uL}, 5.37 \mathrm{mmol})$, and ethanol $(27 \mathrm{~mL})$. After refluxing the reaction mixture for $1.5 \mathrm{~h}$, concentrated under vacuum (note: at this point, there is still unreacted cysteamine disulfide). Silica gel chromatography eluted with 30:1 dichloromethane / methanol yielded 5 as a yellow oil $(157 \mathrm{mg}, 19 \%) ; \quad R_{\mathrm{f}}=0.44(9: 1$ dichloromethane / methanol); ${ }^{1} \mathrm{H}$ NMR $\left(500 \mathrm{MHz}, \mathrm{CDCl}_{3}\right) \delta 8.47$ (ddd, $\left.J=4.8,1.8,0.9 \mathrm{~Hz}, 1 \mathrm{H}\right)$, $7.69(\mathrm{dt}, J=8.0,1.1 \mathrm{~Hz}, 1 \mathrm{H}), 7.63(\mathrm{ddd}, J=8.1,7.3,1.8 \mathrm{~Hz}, 1 \mathrm{H}), 7.09$ (ddd, $J=7.3,4.8,1.1 \mathrm{~Hz}$, $1 \mathrm{H}), 2.93(\mathrm{br} \mathrm{t}, J=1.8 \mathrm{~Hz}, 4 \mathrm{H}), 2.82(\mathrm{t}, J=6.6 \mathrm{~Hz}, 2 \mathrm{H}), 2.43(\mathrm{t}, J=6.5 \mathrm{~Hz}, 2 \mathrm{H}), 1.75(\mathrm{br} \mathrm{s}, 1 \mathrm{H})$, 
$1.45(\mathrm{~s}, 9 \mathrm{H}) ;{ }^{13} \mathrm{C}$ NMR $\left(125 \mathrm{MHz}, \mathrm{CDCl}_{3}\right) \delta 172.1,160.2,149.8,137.1,120.9,120.1,80.8,47.6$, 44.9, 39.1, 36.0, 28.3; HRMS (ESI) $\mathrm{m} / z$ calc'd for $\mathrm{C}_{14} \mathrm{H}_{23} \mathrm{~N}_{2} \mathrm{O}_{2} \mathrm{~S}_{2}[\mathrm{M}+\mathrm{H}]^{+}: 315.1201$, found 315.1202 .

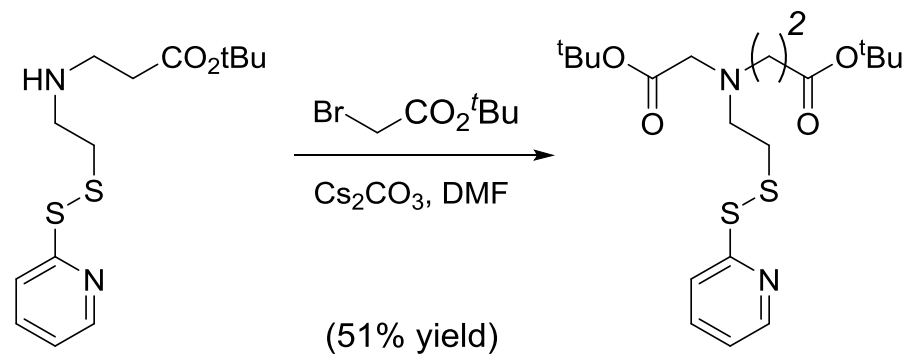

5

$7 a$

To a vial containing amine 5 ( $77.3 \mathrm{mg}, 0.246 \mathrm{mmol}$ ), added tert-butyl bromoacetate (40 $\mu \mathrm{L}, 0.270 \mathrm{mmol})$, cesium carbonate $(88 \mathrm{mg}, 0.270 \mathrm{mmol})$, and DMF $(2.5 \mathrm{~mL})$. After stirring till 5 was consumed by TLC analysis, the reaction mixture was diluted in water $(25 \mathrm{~mL})$ then extracted with diethyl ether $(2 \times 25 \mathrm{~mL})$. After washing the combining organic layers with water $(2 \times 25 \mathrm{~mL})$, dried with $\mathrm{MgSO}_{4}$, filtered, concentrated under vacuum. Purification via preparative TLC (1:1 hexanes / diethyl ether) yielded 7a as a slightly yellow oil (54 mg, 51\%); $R_{\mathrm{f}}=0.62\left(2: 1\right.$ hexanes/ ethyl acetate); ${ }^{1} \mathrm{H} \mathrm{NMR}\left(500 \mathrm{MHz}, \mathrm{CDCl}_{3}\right) \delta 8.45(\mathrm{ddd}, J=4.8,1.9,0.9$ $\mathrm{Hz}, 1 \mathrm{H}), 7.73$ (dt, $J=8.2,1.0 \mathrm{~Hz}, 1 \mathrm{H}), 7.64$ (ddd, $J=8.1,7.4,1.8 \mathrm{~Hz}, 1 \mathrm{H}$ ), 7.07 (ddd, $J=7.4$, 4.8, $1.1 \mathrm{~Hz}, 1 \mathrm{H}), 3.29(\mathrm{~s}, 2 \mathrm{H}), 2.99(\mathrm{~d}, J=8.8 \mathrm{~Hz}, 1 \mathrm{H}), 2.98(\mathrm{~d}, J=7.6 \mathrm{~Hz}, 1 \mathrm{H}), 2.94(\mathrm{t}, J=7.1$ $\mathrm{Hz}, 3 \mathrm{H}), 2.90(\mathrm{~d}, J=7.7 \mathrm{~Hz}, 1 \mathrm{H}), 2.89(\mathrm{~d}, J=8.8 \mathrm{~Hz}, 1 \mathrm{H}), 2.36(\mathrm{t}, J=7.1 \mathrm{~Hz}, 2 \mathrm{H}), 1.43(\mathrm{~s}$, $18 \mathrm{H}) ;{ }^{13} \mathrm{C}$ NMR $\left(125 \mathrm{MHz}, \mathrm{CDCl}_{3}\right) \delta 171.8,170.7,160.6,149.7,137.1,120.7,119.7,81.3,80.5$, 55.8, 53.4, 49.9, 37.6, 34.9, 28.3; HRMS (ESI) $\mathrm{m} / z$ calc'd for $\mathrm{C}_{20} \mathrm{H}_{33} \mathrm{~N}_{2} \mathrm{O}_{4} \mathrm{~S}_{2}[\mathrm{M}+\mathrm{H}]^{+}$: 429.1881, found 429.1877 .

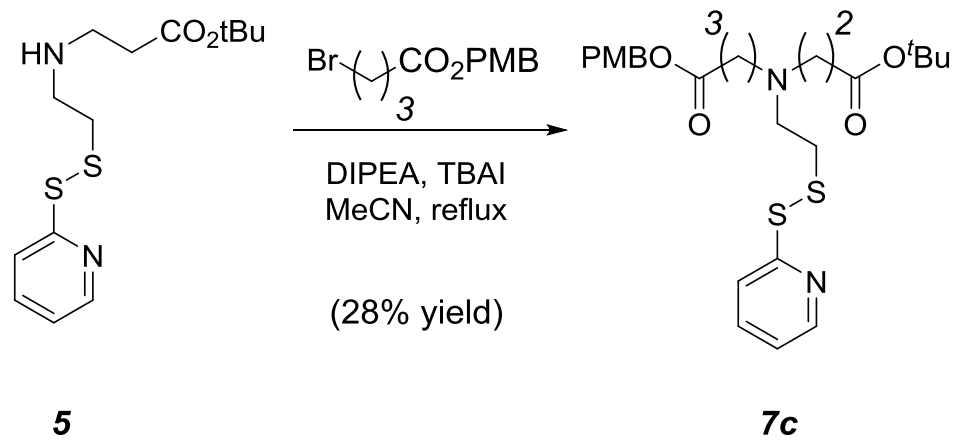

To a flask was added amine 5 (67 $\mathrm{mg}, 0.213 \mathrm{mmol})$, 4-methoxybenzyl 4-bromobutanoate (153 mg, $0.533 \mathrm{mmol}), \mathrm{N}, \mathrm{N}$,-diisopropylethylamine (148 uL,0.852 mmol), tetrabutylammonium iodide $(8 \mathrm{mg}, 0.021 \mathrm{mmol})$, and acetonitrile $(2.1 \mathrm{~mL})$. After refluxing the reaction mixture till 5 was consumed by TLC analysis, added water $(10 \mathrm{~mL})$ then extracted with diethyl ether $(25 \mathrm{~mL})$. The organic layer was subsequently dried with $\mathrm{MgSO}_{4}$, filtered, and concentrated under vacuum. 
Purification via preparative TLC (1:1 hexanes / diethyl ether) yielded 7c as a slightly yellow oil (31mg, 28\%); $R_{\mathrm{f}}=0.40$ (2:1 hexanes / ethyl acetate); ${ }^{1} \mathrm{H}$ NMR $\left(500 \mathrm{MHz}, \mathrm{CDCl}_{3}\right) \delta 8.45$ (ddd, $J$ $=4.9,1.9,0.9 \mathrm{~Hz}, 0 \mathrm{H}), 7.72(\mathrm{dt}, J=8.0,1.1 \mathrm{~Hz}, 1 \mathrm{H}), 7.63(\mathrm{ddd}, J=7.9,7.5,1.8 \mathrm{~Hz}, 1 \mathrm{H}), 7.28$ $(\mathrm{d}, J=8.6 \mathrm{~Hz}, 1 \mathrm{H}), 7.07(\mathrm{ddd}, J=7.4,4.8,1.1 \mathrm{~Hz}, 0 \mathrm{H}), 6.88(\mathrm{~d}, J=8.6 \mathrm{~Hz}, 1 \mathrm{H}), 5.03(\mathrm{~s}, 1 \mathrm{H})$, $3.80(\mathrm{~s}, 2 \mathrm{H}), 2.85(\mathrm{~d}, J=8.4 \mathrm{~Hz}, 1 \mathrm{H}), 2.84(\mathrm{~d}, J=7.4 \mathrm{~Hz}, 1 \mathrm{H}), 2.75(\mathrm{~d}, J=7.5 \mathrm{~Hz}, 1 \mathrm{H}), 2.74(\mathrm{~d}$, $J=8.5 \mathrm{~Hz}, 1 \mathrm{H}), 2.71(\mathrm{t}, J=7.0 \mathrm{~Hz}, 1 \mathrm{H}), 2.43(\mathrm{t}, J=6.9 \mathrm{~Hz}, 1 \mathrm{H}), 2.36(\mathrm{t}, J=7.3 \mathrm{~Hz}, 1 \mathrm{H}), 2.30$ $(\mathrm{t}, J=7.1 \mathrm{~Hz}, 1 \mathrm{H}), 1.74$ (quint, $J=7.1 \mathrm{~Hz}, 1 \mathrm{H}), 1.42(\mathrm{~s}, 5 \mathrm{H}) ;{ }^{13} \mathrm{C} \mathrm{NMR}\left(125 \mathrm{MHz}, \mathrm{CDCl}_{3}\right) \delta$ 173.7, 172.0, 160.6, 159.7, 149.8, 137.1, 130.2, 128.3, 120.7, 119.8, 114.1, 80.5, 66.1, 55.4, 53.1, 52.9, 49.6, 37.2, 33.9, 31.9, 28.3, 22.7; HRMS (ESI) $m / z$ calc'd for $\mathrm{C}_{26} \mathrm{H}_{37} \mathrm{~N}_{2} \mathrm{O}_{5} \mathrm{~S}_{2}[\mathrm{M}+\mathrm{H}]^{+}$: 521.2144, found 521.2142.

General Procedure for Bisboronic Acid Analogs 4a-4c and 9a-9b

$\left(\mathrm{R}={ }^{t} \mathrm{Bu}\right.$ or $\left.\mathrm{PMB}\right)$

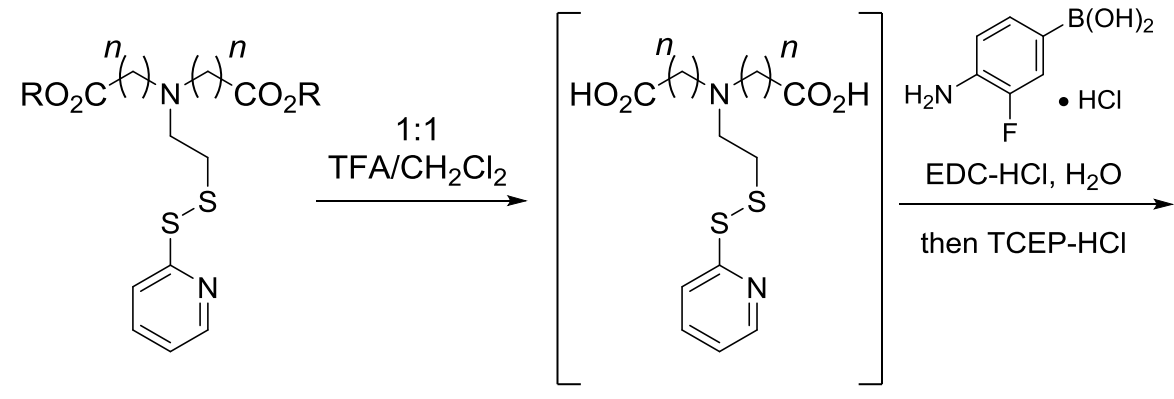

$2 a-c, 7 a-b$

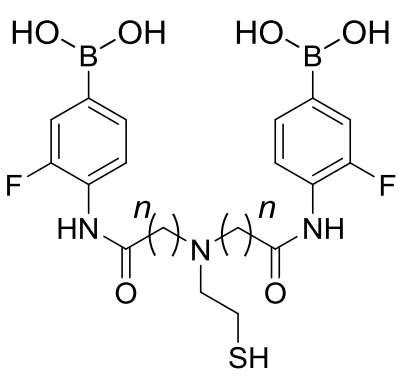

$4 a-c, 9 a-b$

To a vial (1-dram) containing diester 2a-c,7b (1 equiv.), added dichloromethane (0.05 M) then trifluoroacetic acid $(0.05 \mathrm{M})$. After stirring until consumption of $\mathbf{2 b}$ via TLC analysis, transferred the reaction mixture along with a dichloromethane rinse to a conical centrifuge tube $(15 \mathrm{~mL})$. Concentrated down the mixture via passage of nitrogen gas before precipitating diacid $\mathbf{3 a - c , 8 a - b}$ via addition of diethyl ether. Centrifuged the suspension, pipetted off the ether supernatant, then resuspended the resulting white solid pellet in water $(0.1 \mathrm{M})$. Transferred the diacid solution to another vial containing EDC-HCl (3 equiv.) and 4-amino-3-

fluorophenylboronic acid hydrochloride (3 equiv). After stirring for $3 \mathrm{~h}$, checked the progress of the reaction via ESI-MS analysis and added additional equivalents of $\mathrm{EDC}-\mathrm{HCl}$ and aniline if necessary. Thereafter, added tris(2-carboxyethyl) phosphine hydrochloride (1.5 equiv.) directly to the reaction mixture. After $45 \mathrm{~min}-1.5 \mathrm{~h}$, the crude reaction mixture was directly purified via semi-preparative reverse-phase HPLC (see table below for specific elution conditions) and lyophilized to yield $\mathbf{4 a - c , 9 a - b}$ as white puffy solids.

Elution conditions for HPLC purification of bisboronic acids $\mathbf{4 a - c}$, 9a-b

Solvent A - Water with $0.1 \%$ trifluoroacetic acid Solvent B - 75\% Acetonitrile / 25\% Water with $0.1 \%$ trifluoroacetic acid

\begin{tabular}{|l|l|}
\hline Time (min) & Solvent B (\%)
\end{tabular}




\begin{tabular}{|c|c|}
\hline 0 & 0 \\
10 & 0 \\
20 & 25 \\
30 & 45 \\
40 & 45 \\
55 & 65 \\
60 & 100 \\
\hline
\end{tabular}

[Note: The ipso- carbons of phenylboronic acids appear as broad peaks in ${ }^{13} \mathrm{C} \mathrm{NMR} .{ }^{4}$ Also,for ESI-MS analysis, $100 \% \mathrm{H}_{2} \mathrm{O}$ methods were required for observation of protonated molecules.]

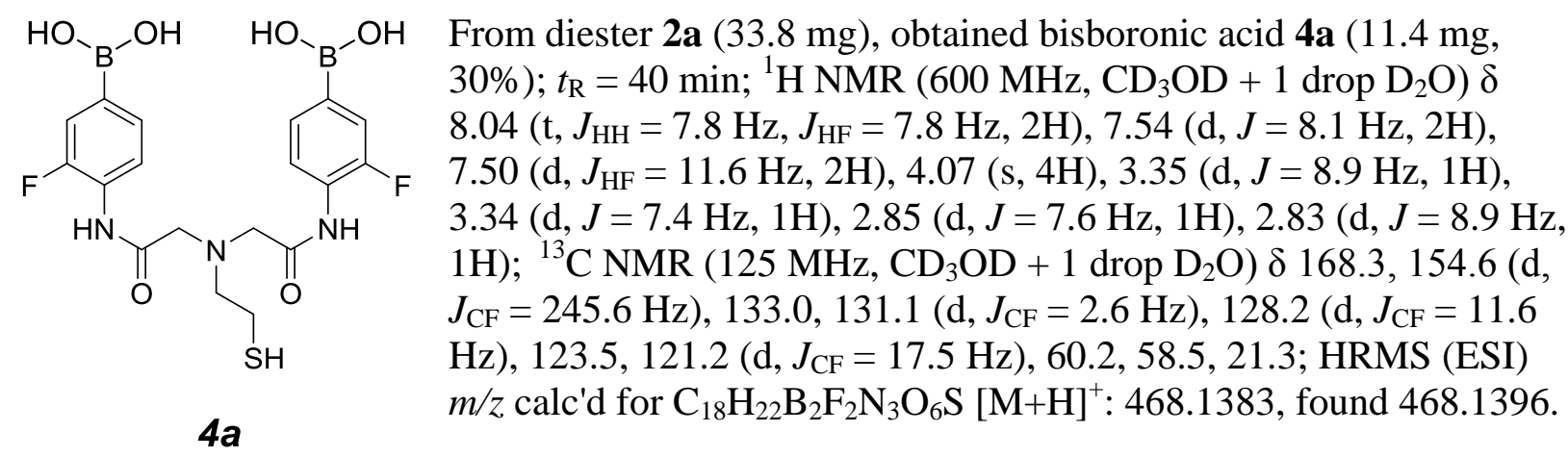

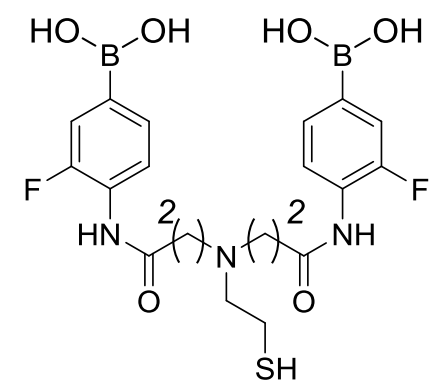

$4 b$
From diester $\mathbf{2 b}$ (33 mg), obtained bisboronic acid $\mathbf{4 b}$ (16.6 mg, $45 \%) ; t_{\mathrm{R}}=35 \mathrm{~min} ;{ }^{1} \mathrm{H} \mathrm{NMR}\left(500 \mathrm{MHz}, \mathrm{CD}_{3} \mathrm{OD}+1\right.$ drop $\left.\mathrm{D}_{2} \mathrm{O}\right) \delta$ $7.95\left(\mathrm{t}, J_{\mathrm{HH}}=7.8 \mathrm{~Hz}, J_{\mathrm{HF}}=7.8 \mathrm{~Hz}, 2 \mathrm{H}\right), 7.48\left(\mathrm{~d}, J_{\mathrm{HF}}=12.4 \mathrm{~Hz}, 2 \mathrm{H}\right)$, $7.45(\mathrm{~d}, J=7.6 \mathrm{~Hz}, 2 \mathrm{H}), 3.62(\mathrm{t}, J=6.0 \mathrm{~Hz}, 2 \mathrm{H}), 3.49(\mathrm{t}, J=6.8 \mathrm{~Hz}$, $2 \mathrm{H}), 3.09$ (br t, $J=6.0 \mathrm{~Hz}, 2 \mathrm{H}), 3.03(\mathrm{t}, J=6.8 \mathrm{~Hz}, 2 \mathrm{H}) ;{ }^{13} \mathrm{C} \mathrm{NMR}$ $\left(125 \mathrm{MHz}, \mathrm{CD}_{3} \mathrm{OD}+1\right.$ drop $\left.\mathrm{D}_{2} \mathrm{O}\right) \delta 171.1,154.6\left(\mathrm{~d}, J_{\mathrm{CF}}=245.5 \mathrm{~Hz}\right)$, $132.9,131.0\left(\mathrm{~d}, J_{\mathrm{CF}}=2.2 \mathrm{~Hz}\right), 128.4\left(\mathrm{~d}, J_{\mathrm{CF}}=11.5 \mathrm{~Hz}\right), 124.0,121.1$ $\left(\mathrm{d}, J_{\mathrm{CF}}=17.6 \mathrm{~Hz}\right.$ ), 58.3, 51.6, 30.5, 19.7; HRMS (ESI) $\mathrm{m} / \mathrm{z}$ calc'd for $\mathrm{C}_{20} \mathrm{H}_{26} \mathrm{~B}_{2} \mathrm{~F}_{2} \mathrm{~N}_{3} \mathrm{O}_{6} \mathrm{~S}[\mathrm{M}+\mathrm{H}]^{+}$: 496.1697, found 496.1709.

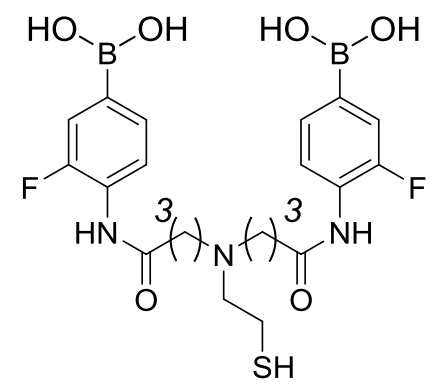

From diester 2c (37.2 mg), obtained bisboronic acid $4 \mathbf{b}(2.9 \mathrm{mg}$, $8.9 \%) ; t_{\mathrm{R}}=35 \mathrm{~min} ;{ }^{1} \mathrm{H}$ NMR $\left(600 \mathrm{MHz}, \mathrm{CD}_{3} \mathrm{OD}+1\right.$ drop $\left.\mathrm{D}_{2} \mathrm{O}\right) \delta$ $7.90\left(\mathrm{t}, J_{\mathrm{HH}}=7.8 \mathrm{~Hz}, J_{\mathrm{HF}}=7.8 \mathrm{~Hz}, 2 \mathrm{H}\right), 7.51(\mathrm{~d}, J=8.3 \mathrm{~Hz}, 2 \mathrm{H})$, $7.48\left(\mathrm{~d}, J_{\mathrm{HF}}=11.8 \mathrm{~Hz}, 2 \mathrm{H}\right), 3.34(\mathrm{t}, J=7.4 \mathrm{~Hz}, 1 \mathrm{H}), 3.44(\mathrm{~d}, J=8.9$ $\mathrm{Hz}, 1 \mathrm{H}), 3.43$ (d, $J=7.8 \mathrm{~Hz}, 1 \mathrm{H}), 3.33$ (t, $J=7.8 \mathrm{~Hz}, 4 \mathrm{H}), 2.93(\mathrm{~d}, J$ 
$=7.8 \mathrm{~Hz}, 1 \mathrm{H}), 2.92(\mathrm{~d}, J=9.1 \mathrm{~Hz}, 1 \mathrm{H}), 2.68(\mathrm{t}, J=6.6 \mathrm{~Hz}, 4 \mathrm{H}), 2.12(\mathrm{tt}, J=7.8,6.7 \mathrm{~Hz}, 4 \mathrm{H})$;

${ }^{13} \mathrm{C}$ NMR $\left(125 \mathrm{MHz}, \mathrm{CD}_{3} \mathrm{OD}+1\right.$ drop $\left.\mathrm{D}_{2} \mathrm{O}\right) \delta 173.2,155.0\left(\mathrm{~d}, J_{\mathrm{CF}}=245.5 \mathrm{~Hz}\right), 133.0,130.9(\mathrm{~d}$, $\left.J_{\mathrm{CF}}=2.7 \mathrm{~Hz}\right), 128.5\left(\mathrm{~d}, J_{\mathrm{CF}}=12.3 \mathrm{~Hz}\right), 124.2,121.2\left(\mathrm{~d}, J_{\mathrm{CF}}=17.8 \mathrm{~Hz}\right), 57.1,54.2,33.7,20.4$, 19.2; HRMS (ESI) $m / z$ calc'd for $\mathrm{C}_{22} \mathrm{H}_{30} \mathrm{~B}_{2} \mathrm{~F}_{2} \mathrm{~N}_{3} \mathrm{O}_{6} \mathrm{~S}[\mathrm{M}+\mathrm{H}]^{+}$:

524.2009, found 524.2026.

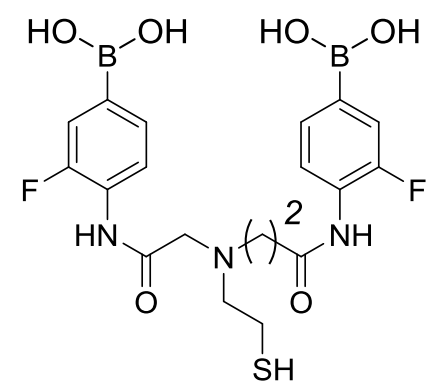

$9 a$

From diester $\mathbf{2 b}(26.7 \mathrm{mg})$, obtained bisboronic acid $\mathbf{4 b}(12.0 \mathrm{mg}$, $40 \%) ; t_{\mathrm{R}}=35 \mathrm{~min} ;{ }^{1} \mathrm{H} \mathrm{NMR}\left(500 \mathrm{MHz}, \mathrm{CD}_{3} \mathrm{OD}+1\right.$ drop $\left.\mathrm{D}_{2} \mathrm{O}\right) \delta$ $8.04\left(\mathrm{t}, J_{\mathrm{HH}}=7.9 \mathrm{~Hz}, J_{\mathrm{HF}}=7.9 \mathrm{~Hz}, 1 \mathrm{H}\right), 7.98\left(\mathrm{t}, J_{\mathrm{HH}}=7.8 \mathrm{~Hz}, J_{\mathrm{HF}}=\right.$ $7.8 \mathrm{~Hz}, 1 \mathrm{H}), 7.59-7.44(\mathrm{~m}, 4 \mathrm{H}), 4.29(\mathrm{~s}, 2 \mathrm{H}), 3.69$ (t, $J=6.4 \mathrm{~Hz}, 2 \mathrm{H})$, $3.52(\mathrm{~d}, J=9.0 \mathrm{~Hz}, 1 \mathrm{H}), 3.51(\mathrm{~d}, J=7.5 \mathrm{~Hz}, 1 \mathrm{H}), 3.05(\mathrm{t}, J=6.4 \mathrm{~Hz}$, 2H), $2.96(\mathrm{~d}, J=7.6 \mathrm{~Hz}, 1 \mathrm{H}), 2.95(\mathrm{~d}, J=9.0 \mathrm{~Hz}, 1 \mathrm{H}) ;{ }^{13} \mathrm{C} \mathrm{NMR}$ $\left(125 \mathrm{MHz}, \mathrm{CD}_{3} \mathrm{OD}+1 \operatorname{drop} \mathrm{D}_{2} \mathrm{O}\right) \delta 170.9,165.2,154.7\left(\mathrm{~d}, J_{\mathrm{CF}}=\right.$ $245.4 \mathrm{~Hz}), 154.5\left(\mathrm{~d}, J_{\mathrm{CF}}=245.8 \mathrm{~Hz}\right), 133.3,132.9,131.1\left(\mathrm{~d}, J_{\mathrm{CF}}=3.4\right.$ $\mathrm{Hz}), 130.9\left(\mathrm{~d}, J_{\mathrm{CF}}=3.4 \mathrm{~Hz}\right), 128.4\left(\mathrm{~d}, J_{\mathrm{CF}}=11.5 \mathrm{~Hz}\right), 127.9\left(\mathrm{~d}, J_{\mathrm{CF}}=\right.$ $11.5 \mathrm{~Hz}), 123.9,123.4,121.2\left(\mathrm{~d}, J_{\mathrm{CF}}=17.4 \mathrm{~Hz}\right), 121.1\left(\mathrm{~d}, J_{\mathrm{CF}}=17.5\right.$ $\mathrm{Hz}$ ), 59.5, 56.7, 52.66, 31.3, 19.6; HRMS (ESI) $m / z$ calc'd for $\mathrm{C}_{19} \mathrm{H}_{24} \mathrm{~B}_{2} \mathrm{~F}_{2} \mathrm{~N}_{3} \mathrm{O}_{6} \mathrm{~S}[\mathrm{M}+\mathrm{H}]^{+}: 482.1540$, found 482.1550

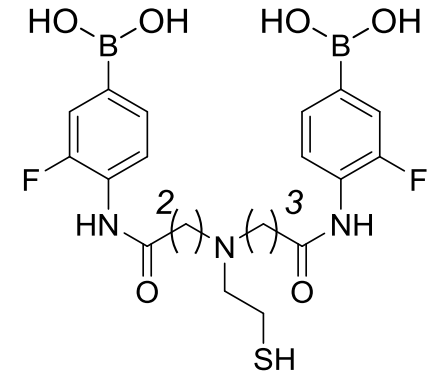

$9 b$

From diester $7 \mathbf{b}(30.7 \mathrm{mg})$, obtained bisboronic acid $\mathbf{4 b}(3.8 \mathrm{mg}$, $13 \%) ; t_{\mathrm{R}}=35 \mathrm{~min} ;{ }^{1} \mathrm{H} \mathrm{NMR}\left(600 \mathrm{MHz}, \mathrm{CD}_{3} \mathrm{OD}+1\right.$ drop $\left.\mathrm{D}_{2} \mathrm{O}\right) \delta$ $7.97\left(\mathrm{t}, J_{\mathrm{HH}}=7.9 \mathrm{~Hz}, J_{\mathrm{HF}}=7.9 \mathrm{~Hz}, 1 \mathrm{H}\right), 7.86\left(\mathrm{t}, J_{\mathrm{HH}}=7.8 \mathrm{~Hz}, J_{\mathrm{HF}}=\right.$ $7.8 \mathrm{~Hz}, 1 \mathrm{H}), 7.53-7.38(\mathrm{~m}, 4 \mathrm{H}), 3.71-3.62(\mathrm{~m}, 1 \mathrm{H}), 3.62-3.53(\mathrm{~m}$, $1 \mathrm{H}), 3.50-3.44(\mathrm{~m}, 2 \mathrm{H}), 3.36(\mathrm{t}, J=7.3 \mathrm{~Hz}, 2 \mathrm{H}), 3.07-3.02(\mathrm{~m}$, $2 \mathrm{H}), 3.01-2.95(\mathrm{~m}, 2 \mathrm{H}), 2.72(\mathrm{br} \mathrm{t}, J=6.6 \mathrm{~Hz}, 1 \mathrm{H}), 2.15(\mathrm{tt}, J=7.1$ $\mathrm{Hz}, J=6.6 \mathrm{~Hz}, 2 \mathrm{H}) ;{ }^{13} \mathrm{C}$ NMR $\left(125 \mathrm{MHz}, \mathrm{CD}_{3} \mathrm{OD}+1 \operatorname{drop~} \mathrm{D}_{2} \mathrm{O}\right) \delta$ $173.5,170.7,154.9\left(\mathrm{~d}, J_{\mathrm{CF}}=245.2 \mathrm{~Hz}\right), 154.6\left(\mathrm{~d}, J_{\mathrm{CF}}=245.4 \mathrm{~Hz}\right)$, $132.9,131.0,128.4\left(\mathrm{~d}, J_{\mathrm{CF}}=11.3 \mathrm{~Hz}\right), 124.1,123.8,121.1\left(\mathrm{~d}, J_{\mathrm{CF}}=\right.$ $17.8 \mathrm{~Hz}$ ), 57.7, 54.6, 51.0, 33.9, 30.9, 20.3, 19.4; HRMS (ESI) $\mathrm{m} / \mathrm{z}$ calc'd for $\mathrm{C}_{21} \mathrm{H}_{28} \mathrm{~B}_{2} \mathrm{~F}_{2} \mathrm{~N}_{3} \mathrm{O}_{6} \mathrm{~S}[\mathrm{M}+\mathrm{H}]^{+}:$510.1853, found 510.1860 .

\subsection{Determination of Equilibrium Constants for Binding of Sugars to Bisboronic Acids}

We used UV-Vis spectroscopy to monitor the extent of complex formation in solutions containing bis-boronic acid receptor and either glucose or fructose (Figure 1, S1, and S2). Stock solutions of the bisboronic acids (4a-c, 9a-b) and sugars were prepared in methanol and $\mathrm{pH} 7.61$ $\mathrm{X}$ PBS buffer, respectively. Experiments were performed in 4-10\% $\mathrm{MeOH}$ in PBS buffer with concentrations of bisboronic acid ranging from 40 to $100 \mu \mathrm{M}$, fructose from 0 to $10 \mathrm{mM}$, and glucose from 0 to $500 \mathrm{mM}$. Solutions were prepared in a vial, mixed, then transferred to a cuvette and analyzed via UV-Vis within one minute from solution preparation. 

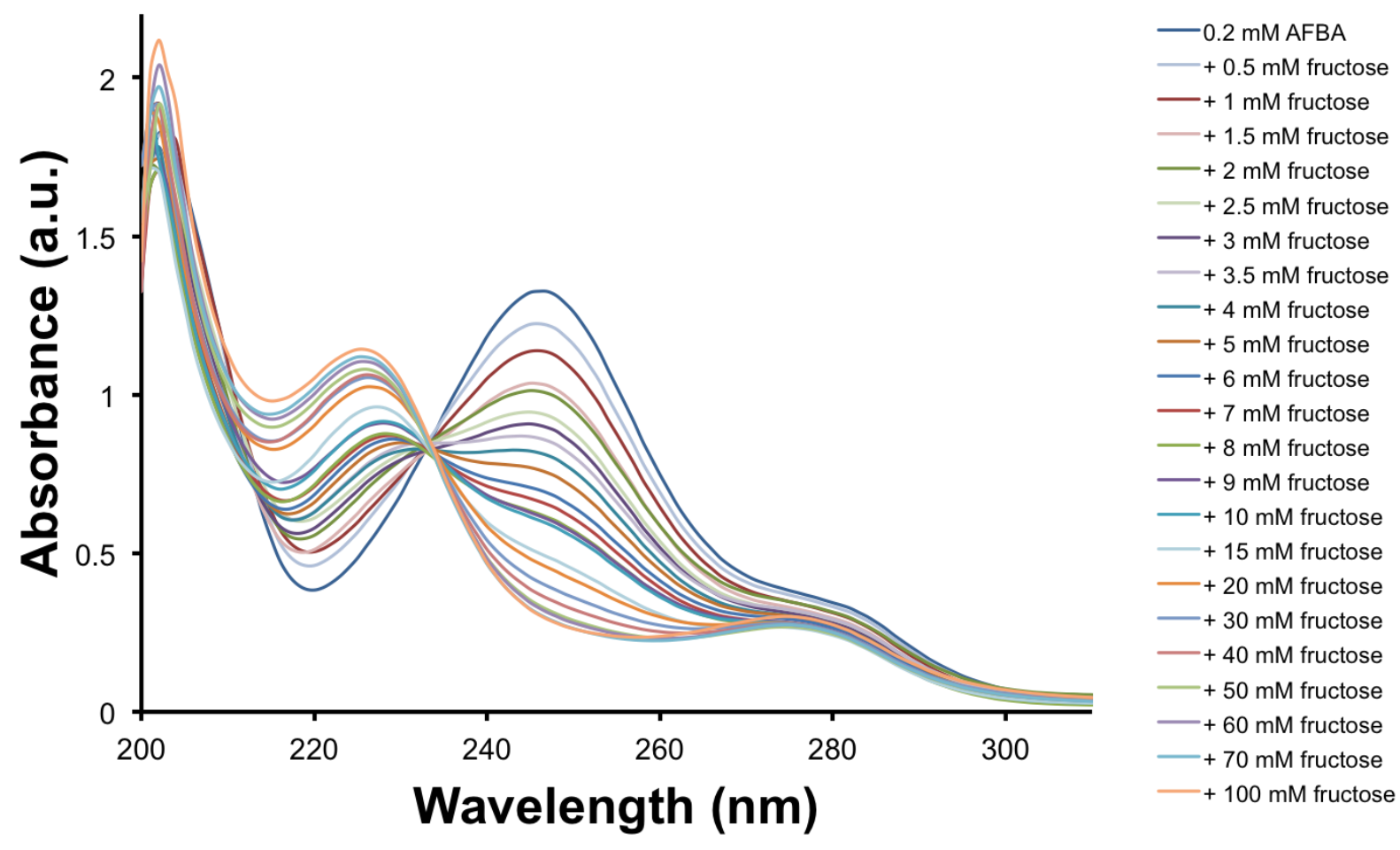

Figure S1. UV-vis absorption spectra of the concentration dependent binding of 4-amino-3-fluorophenylboronic acid with fructose. The calculated binding constant for fructose is $\mathrm{K} \sim 200 \mathrm{M}^{-1}$.
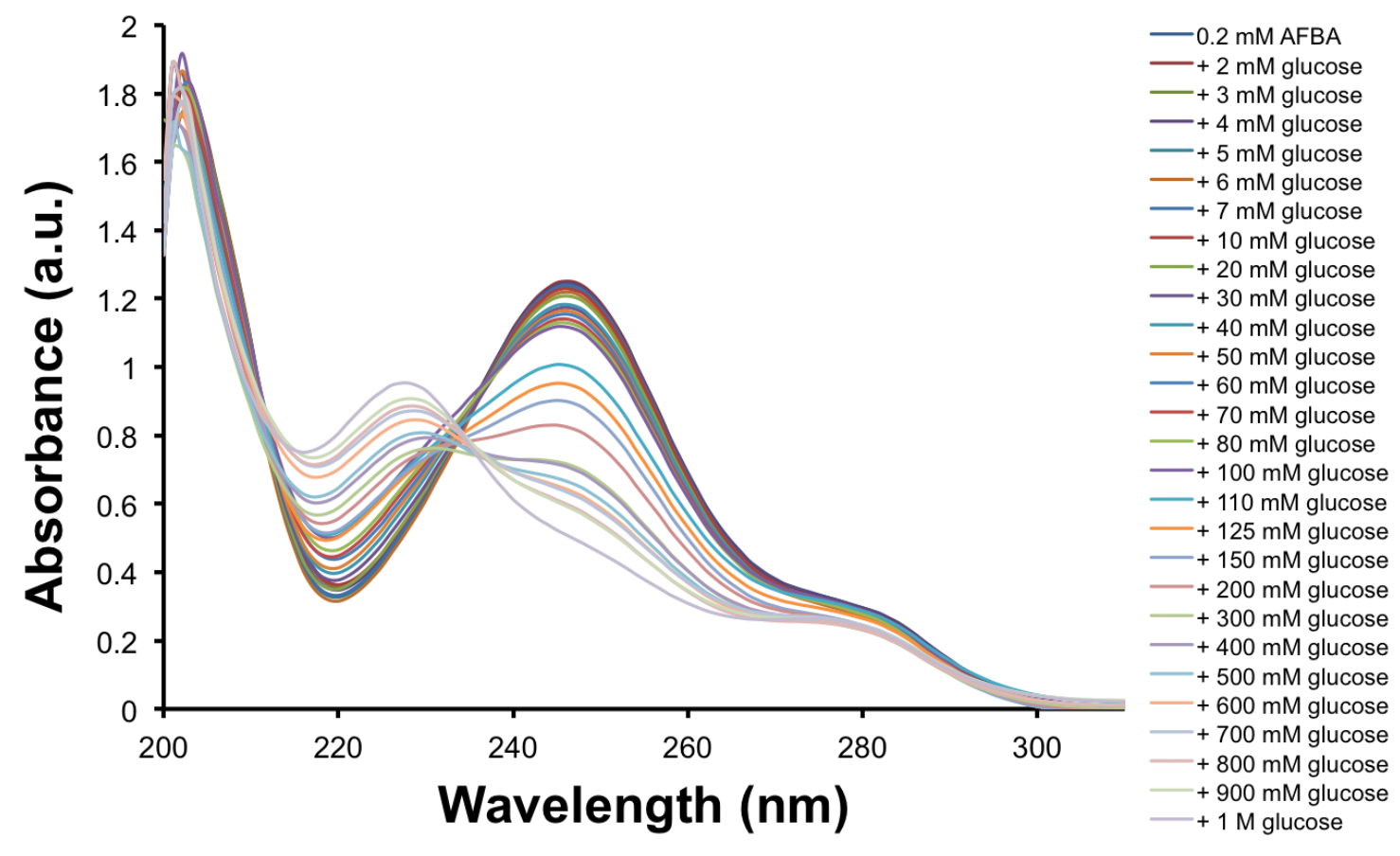
Figure S2. UV-vis absorption spectra of the concentration dependent binding of 4-amino-3-fluorophenylboronic acid with glucose. The calculated binding constant for glucose is $\mathrm{K} \sim 10 \mathrm{M}^{-1}$. The two isosbestic points indicate mono and di-adduct formation.

For each concentration of sugar, we determined the absorbance in the 230-232 nm range. We then measured the change in absorbance for each sequential addition of sugar and plotted the ratio of this change and the concentration of sugar $(\Delta \mathrm{A} /[$ sugar $])$ against the change in absorbance $(\Delta \mathrm{A})$. Using the Scatchard equation, we determined the best-fit slope of this line; the negative of this slope is the binding constant $\mathrm{K}$. Each binding constant value corresponds to one set of UV-Vis titrations.

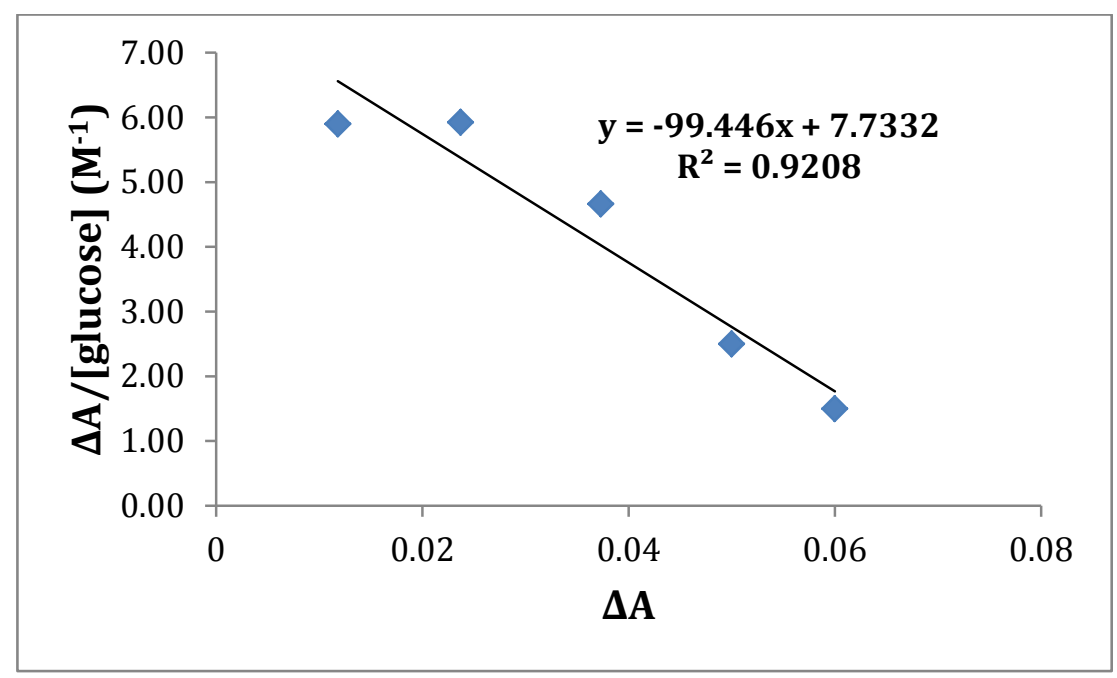

Figure S3. Representative Scatchard plot for the binding of $n, n=2,3$ bisboronic acid (9b) with glucose 
2.3 NMR spectra 


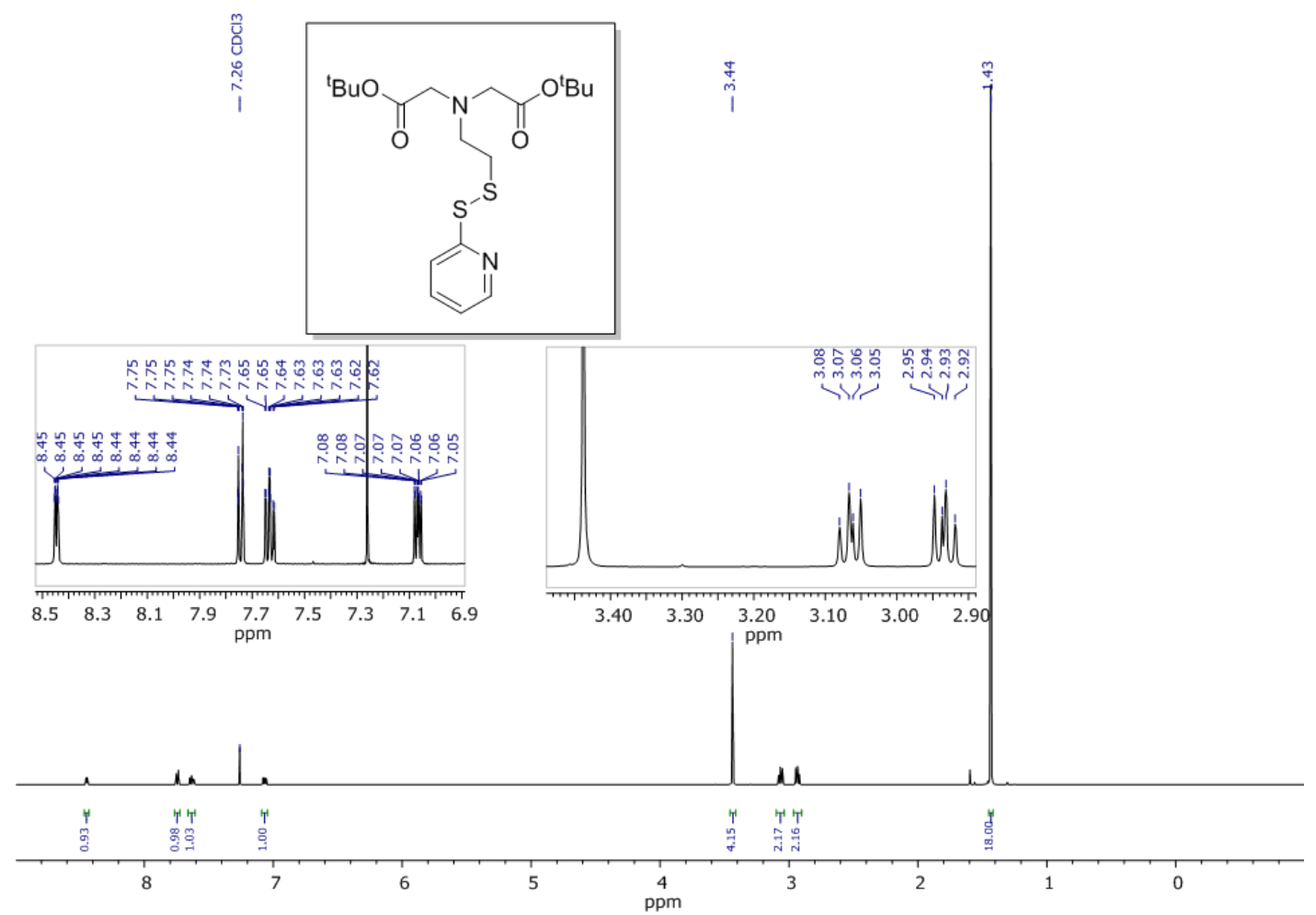

${ }^{1} \mathrm{H}$ NMR (500 MHz, $\mathrm{CDCl}_{3}$ ) of compound $\mathbf{2 a}$

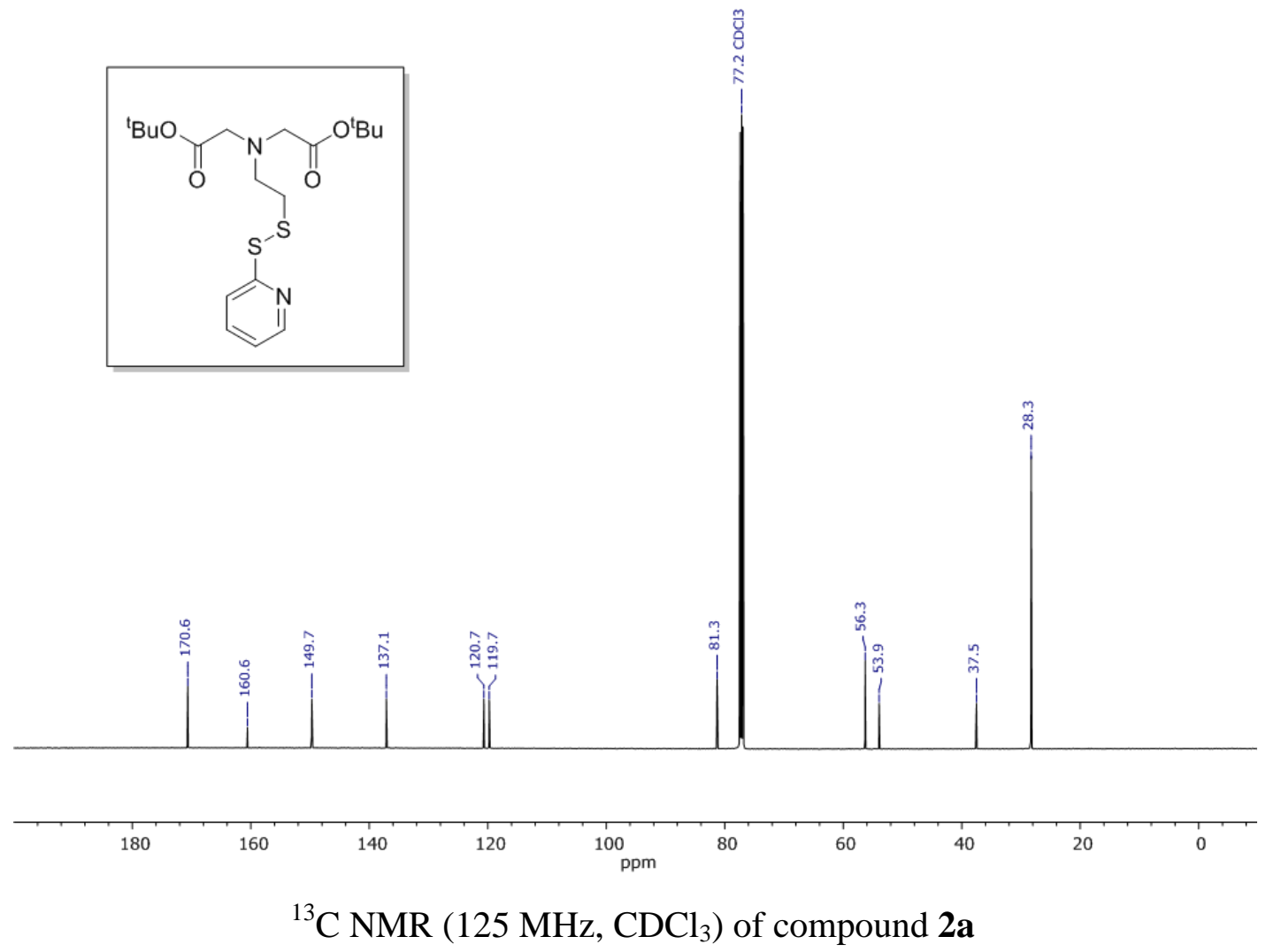




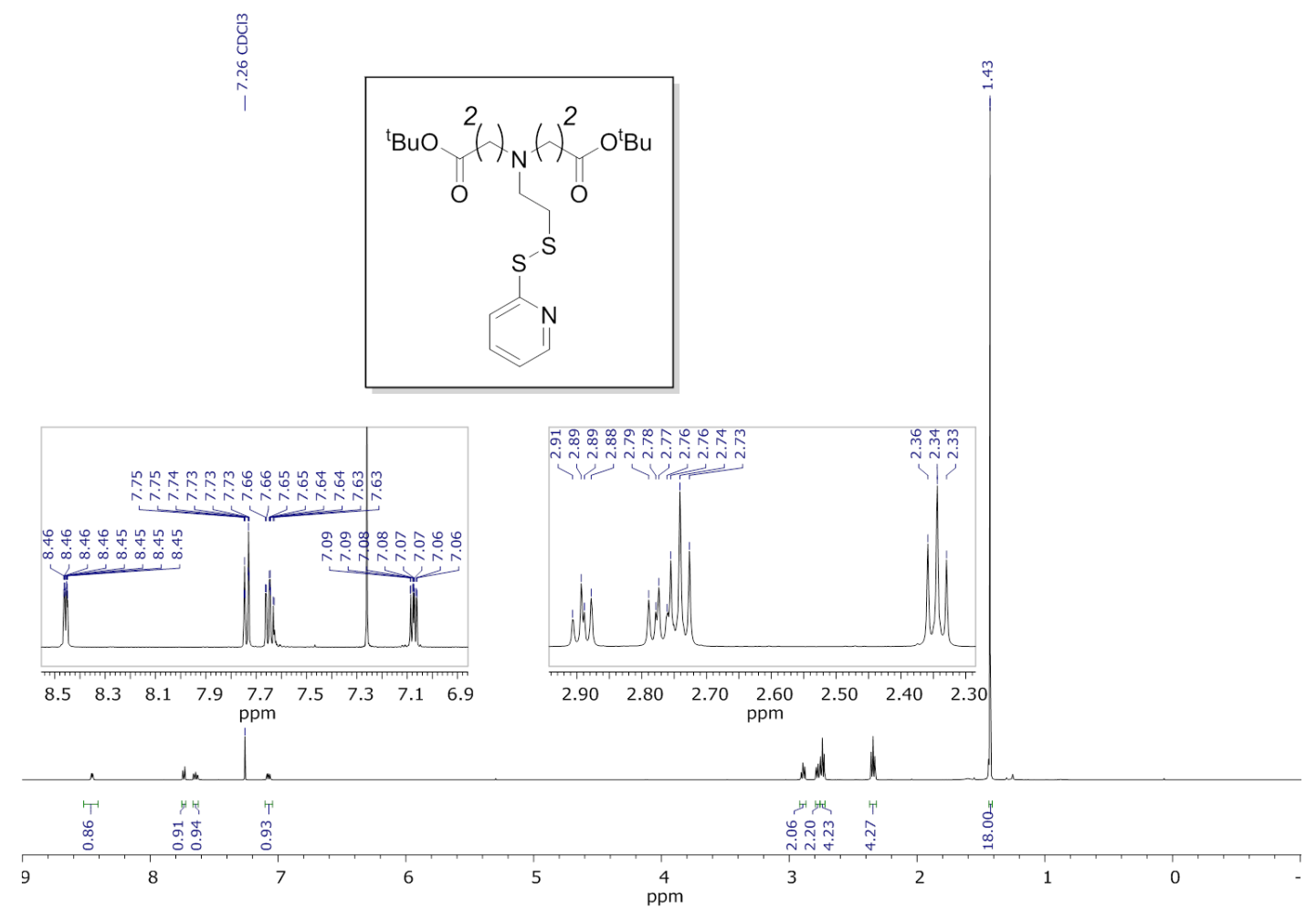

${ }^{1} \mathrm{H}$ NMR (500 MHz, $\mathrm{CDCl}_{3}$ ) of compound $\mathbf{2 b}$

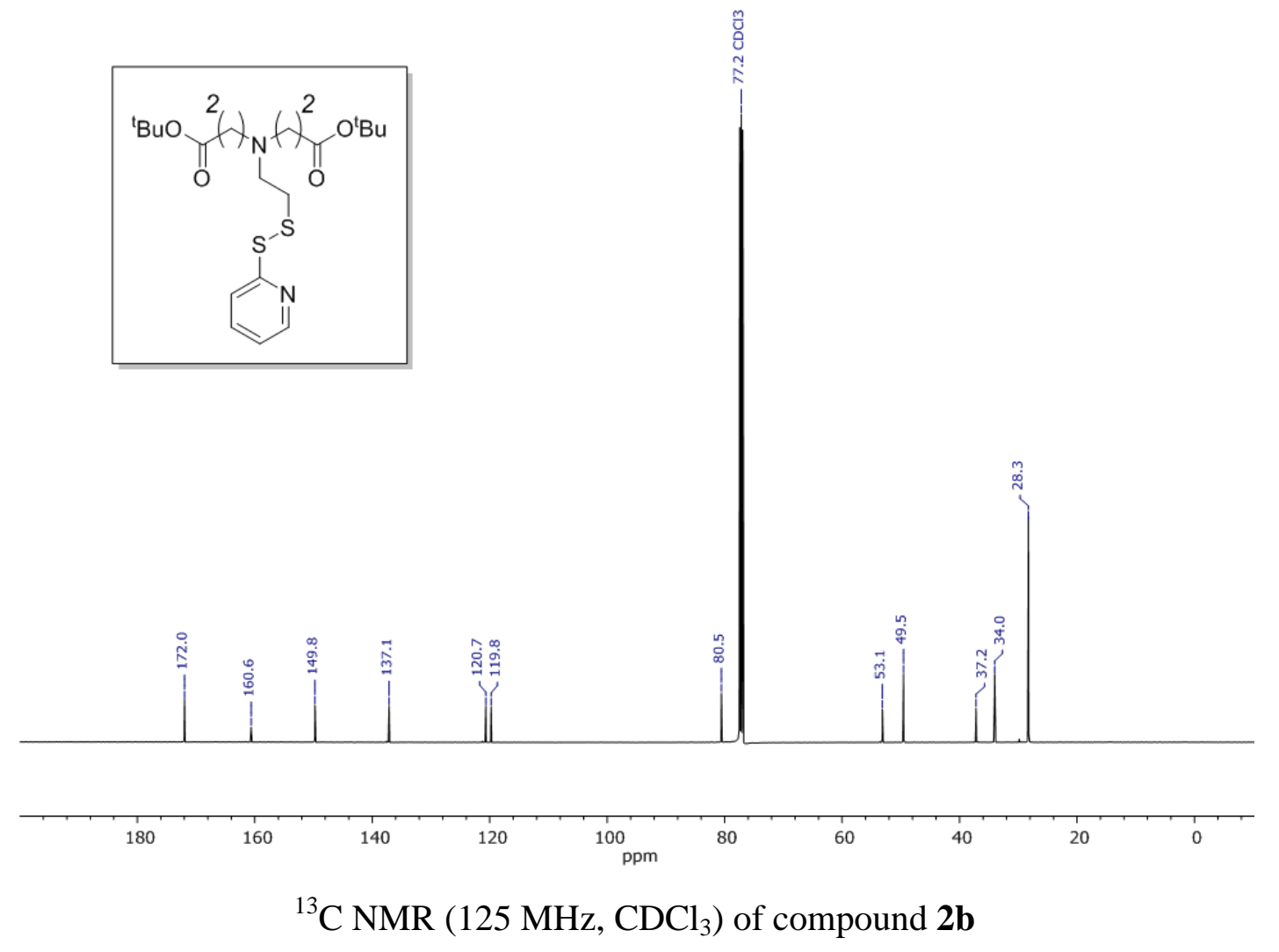



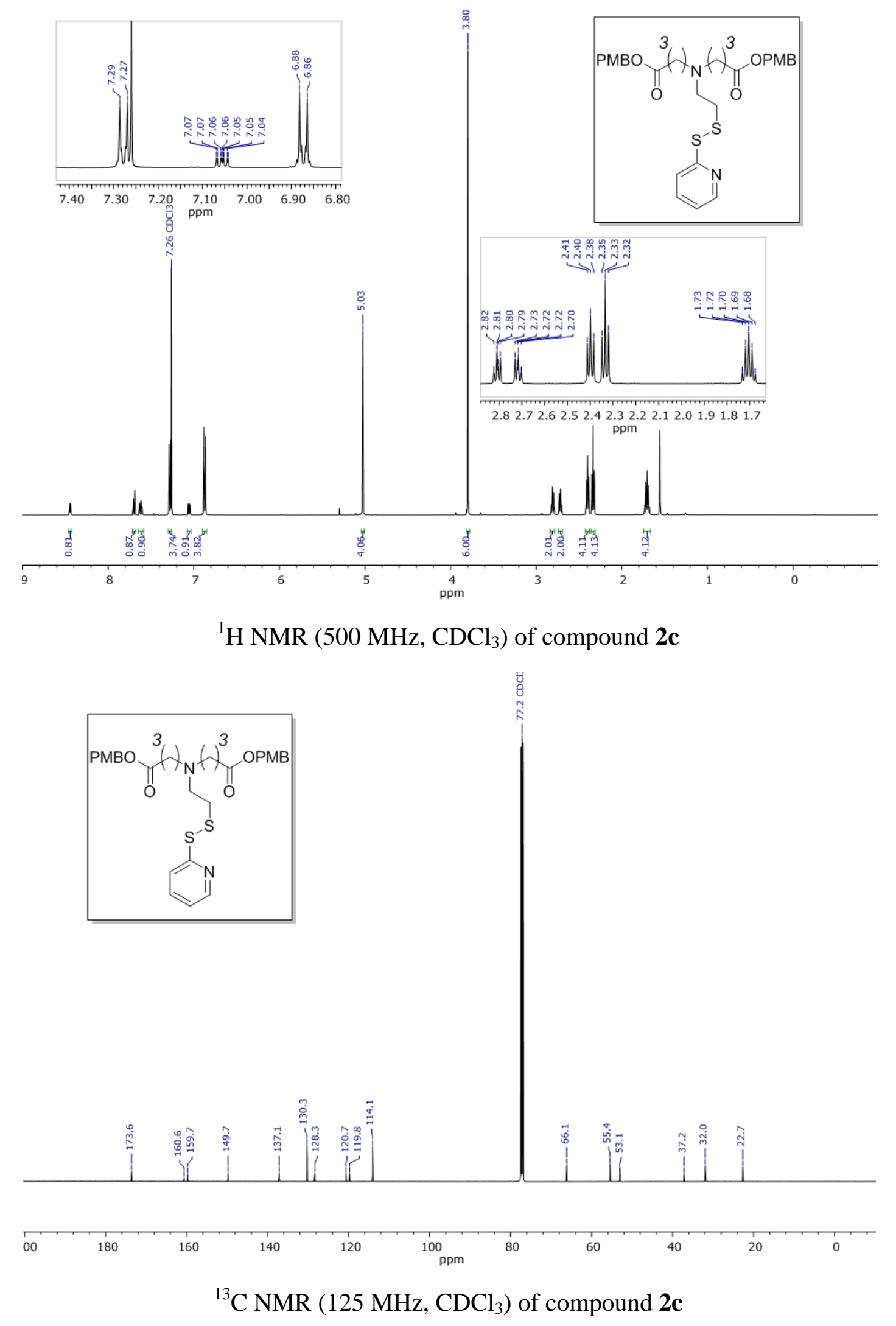


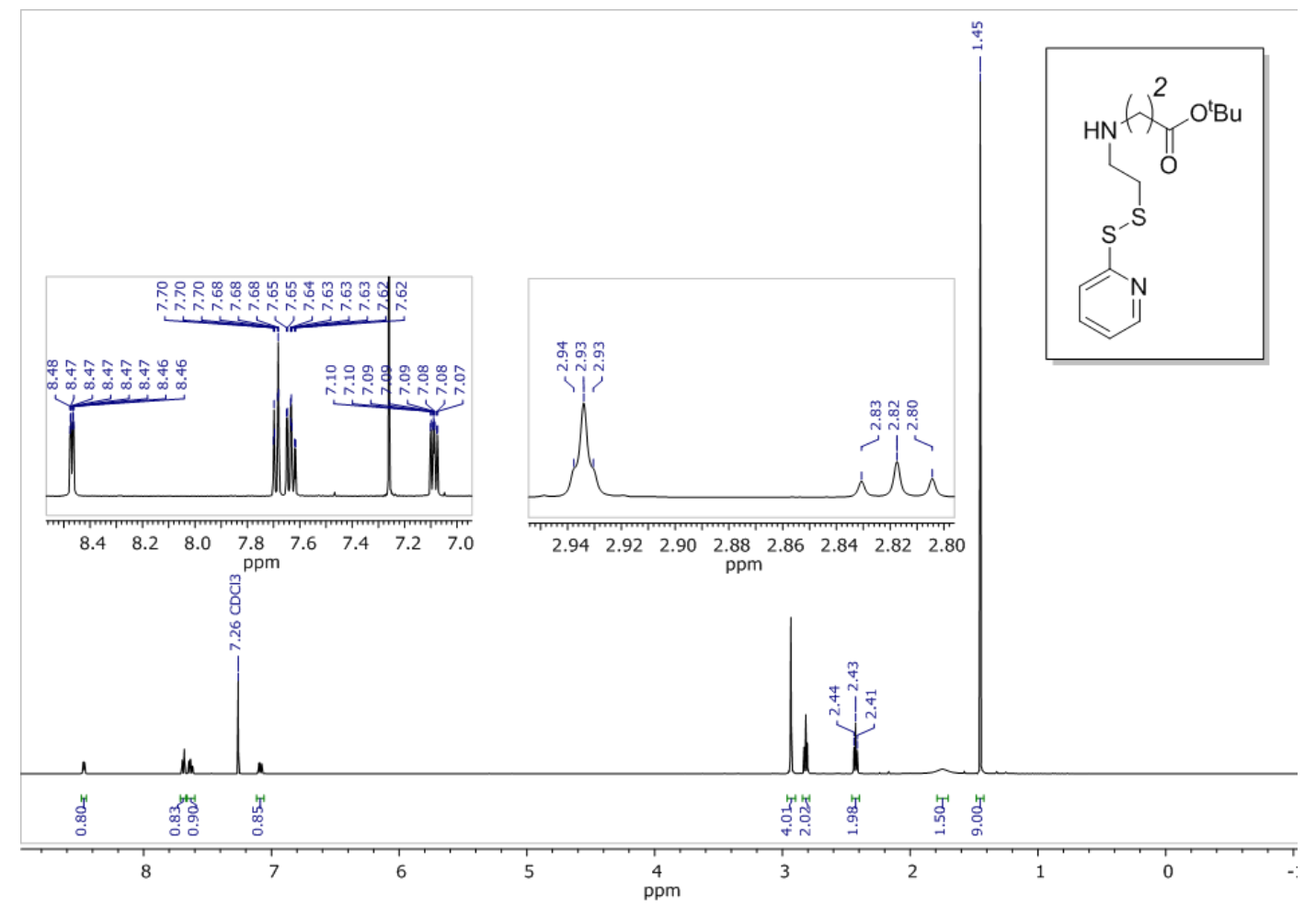

${ }^{1} \mathrm{H}$ NMR (500 MHz, $\mathrm{CDCl}_{3}$ ) of compound 5
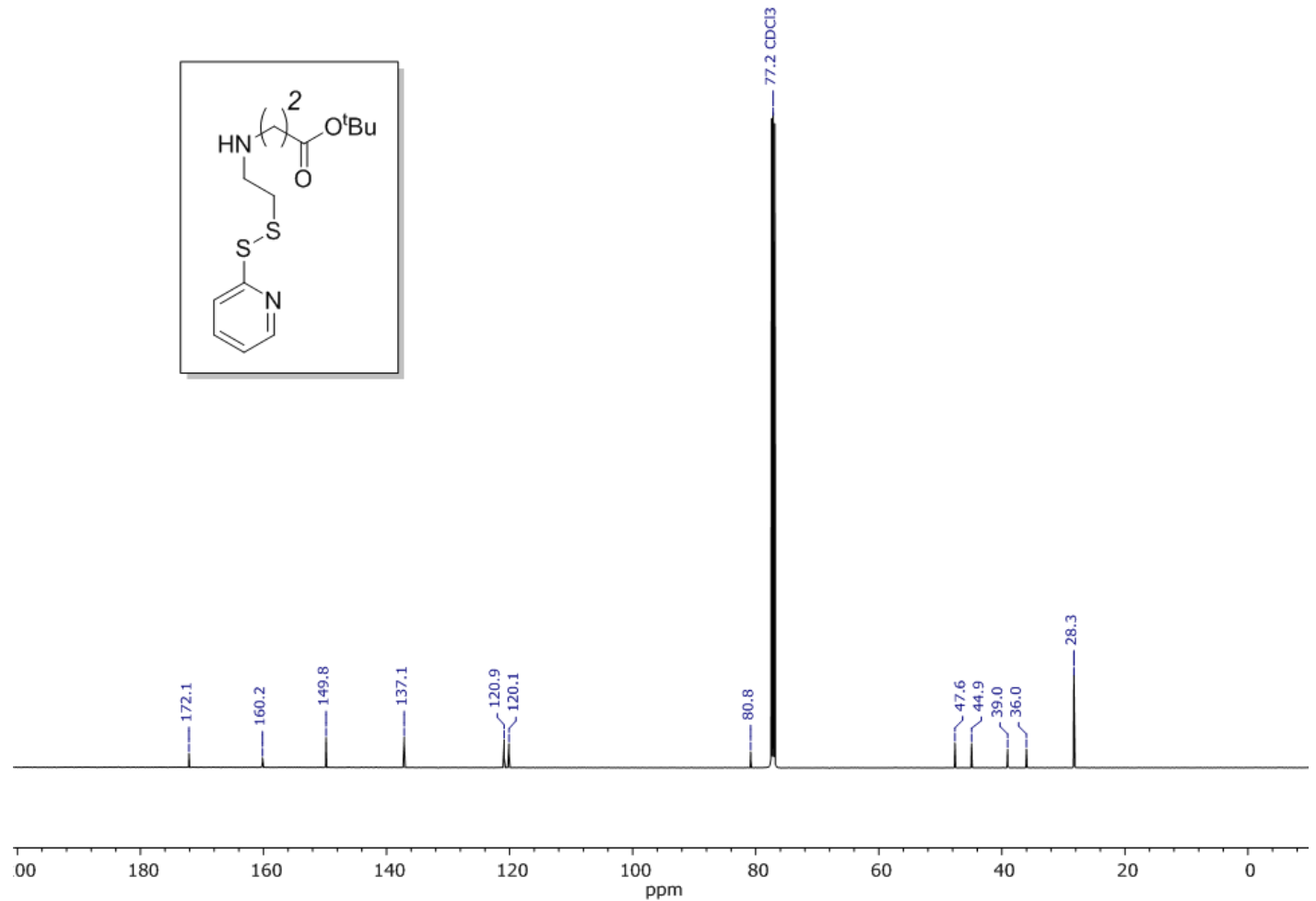

${ }^{13} \mathrm{C}$ NMR $\left(125 \mathrm{MHz}, \mathrm{CDCl}_{3}\right)$ of compound 5 


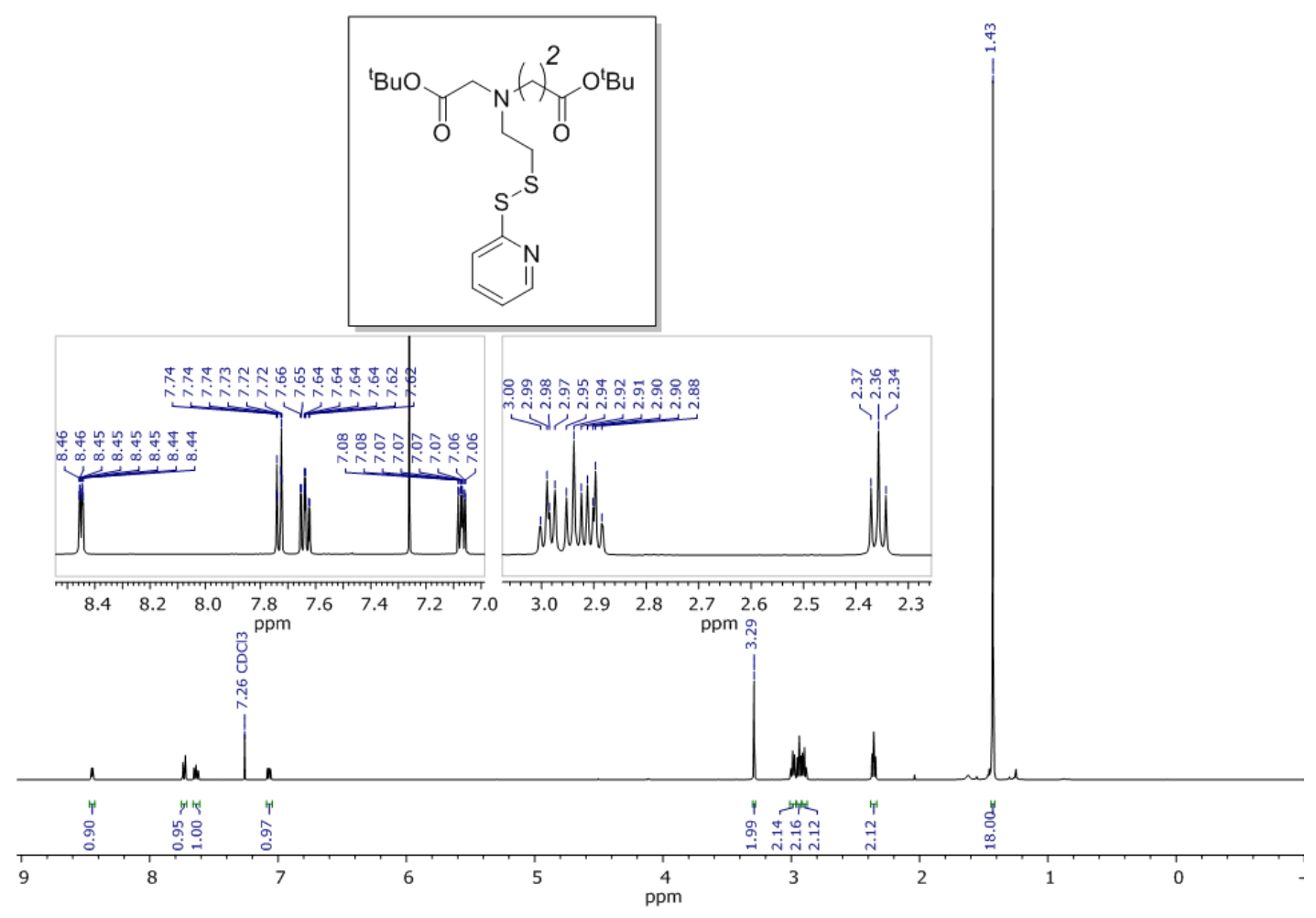

${ }^{1} \mathrm{H}$ NMR $\left(500 \mathrm{MHz}, \mathrm{CDCl}_{3}\right.$ ) of compound 7a
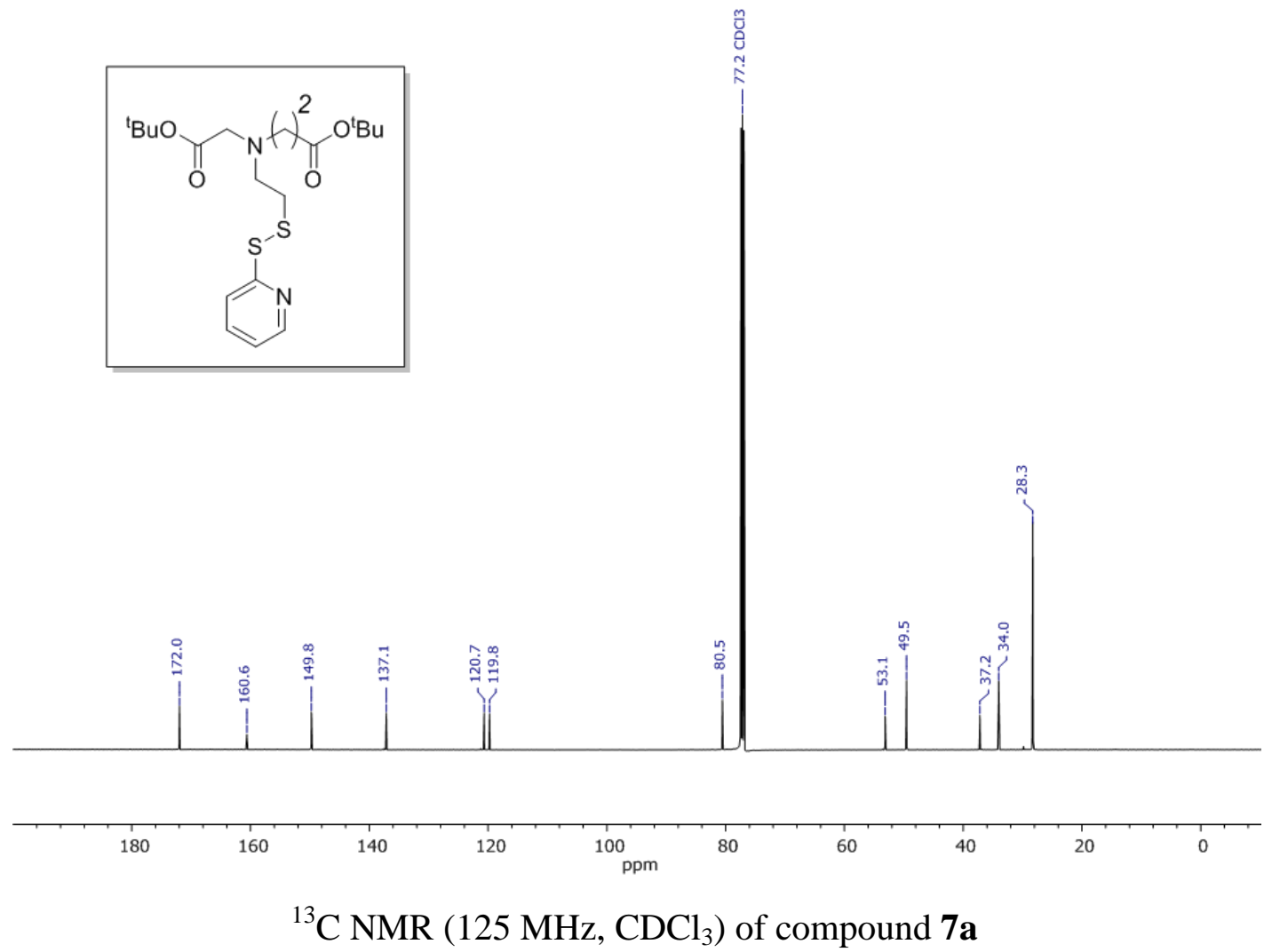

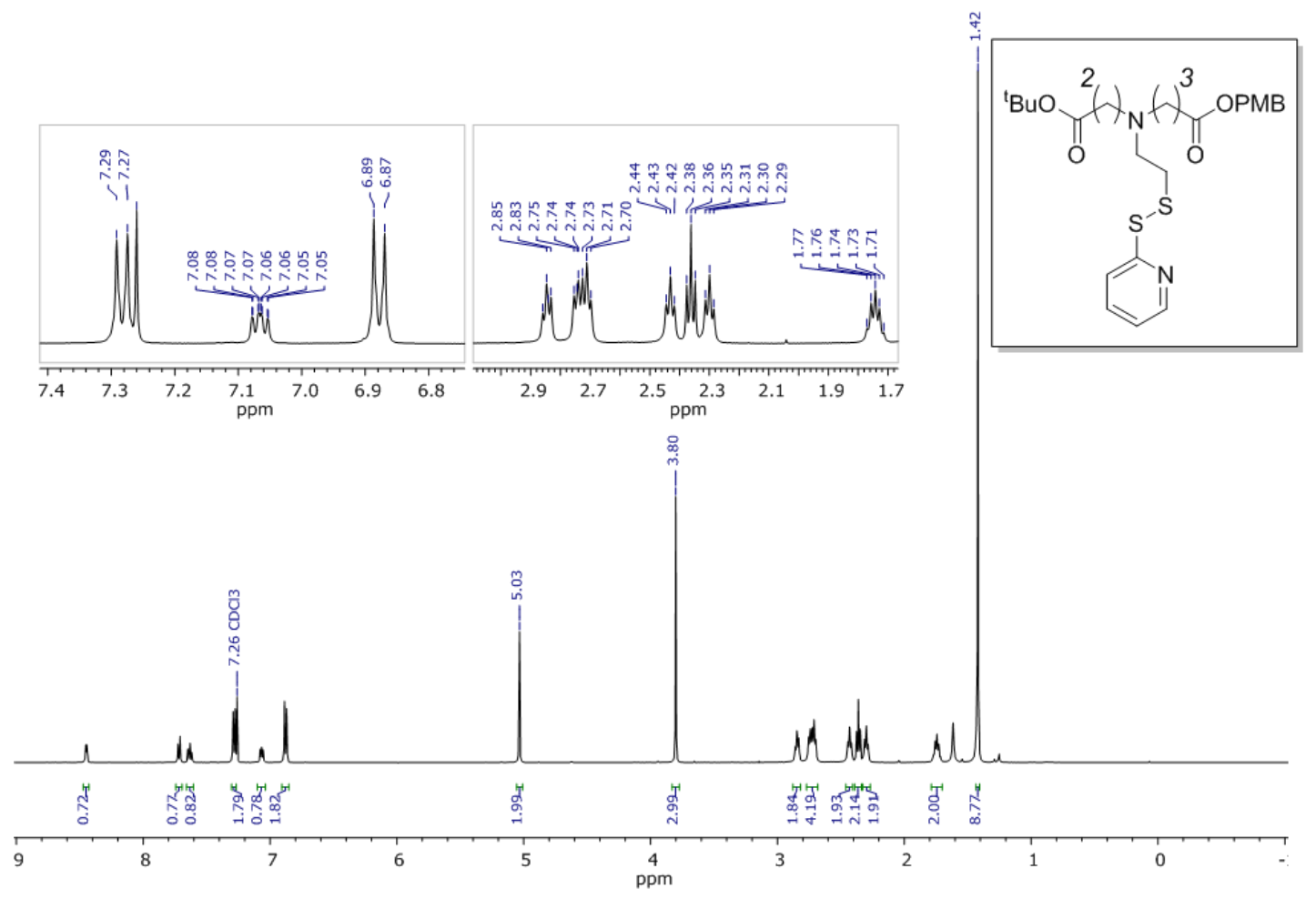

${ }^{1} \mathrm{H}$ NMR (500 MHz, $\mathrm{CDCl}_{3}$ ) of compound $\mathbf{7 b}$
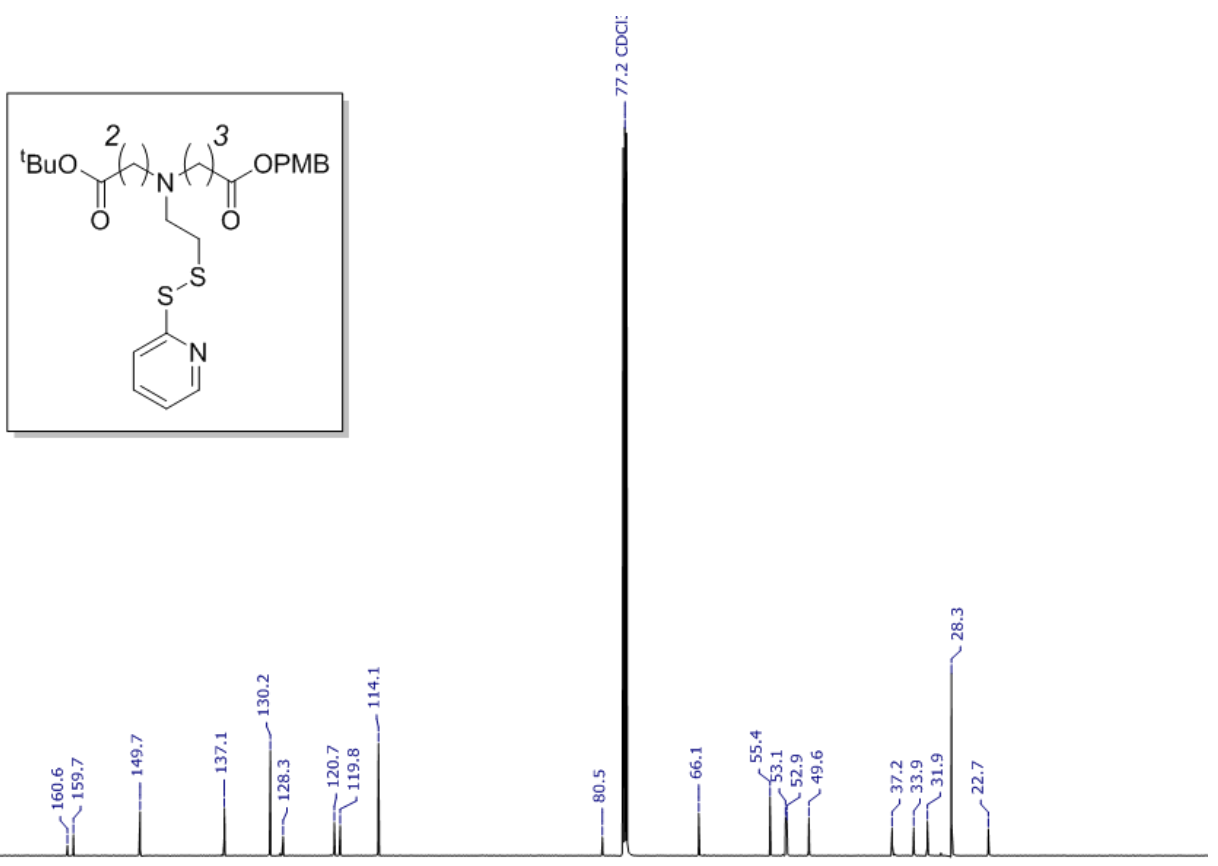

00

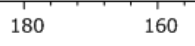

140

120

100

80

60

40

${ }^{13} \mathrm{C}$ NMR (125 MHz, $\mathrm{CDCl}_{3}$ ) of compound $\mathbf{7 b}$ 


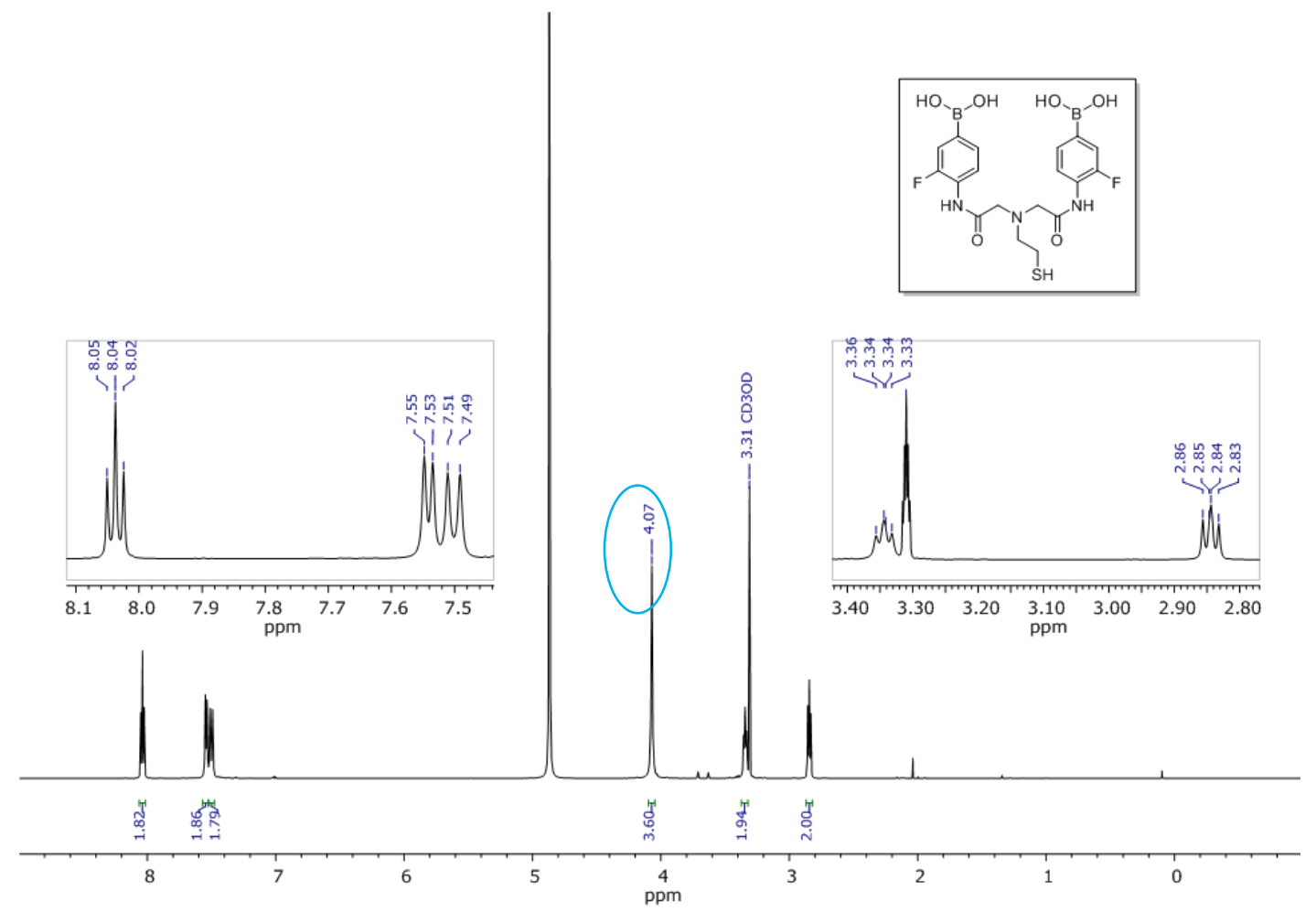

${ }^{1} \mathrm{H}$ NMR $\left(600 \mathrm{MHz}, \mathrm{CD}_{3} \mathrm{OD}+1\right.$ drop $\left.\mathrm{D}_{2} \mathrm{O}\right)$ of compound $4 \mathbf{a}\left[{ }^{19}\right.$ F-coupled $]$
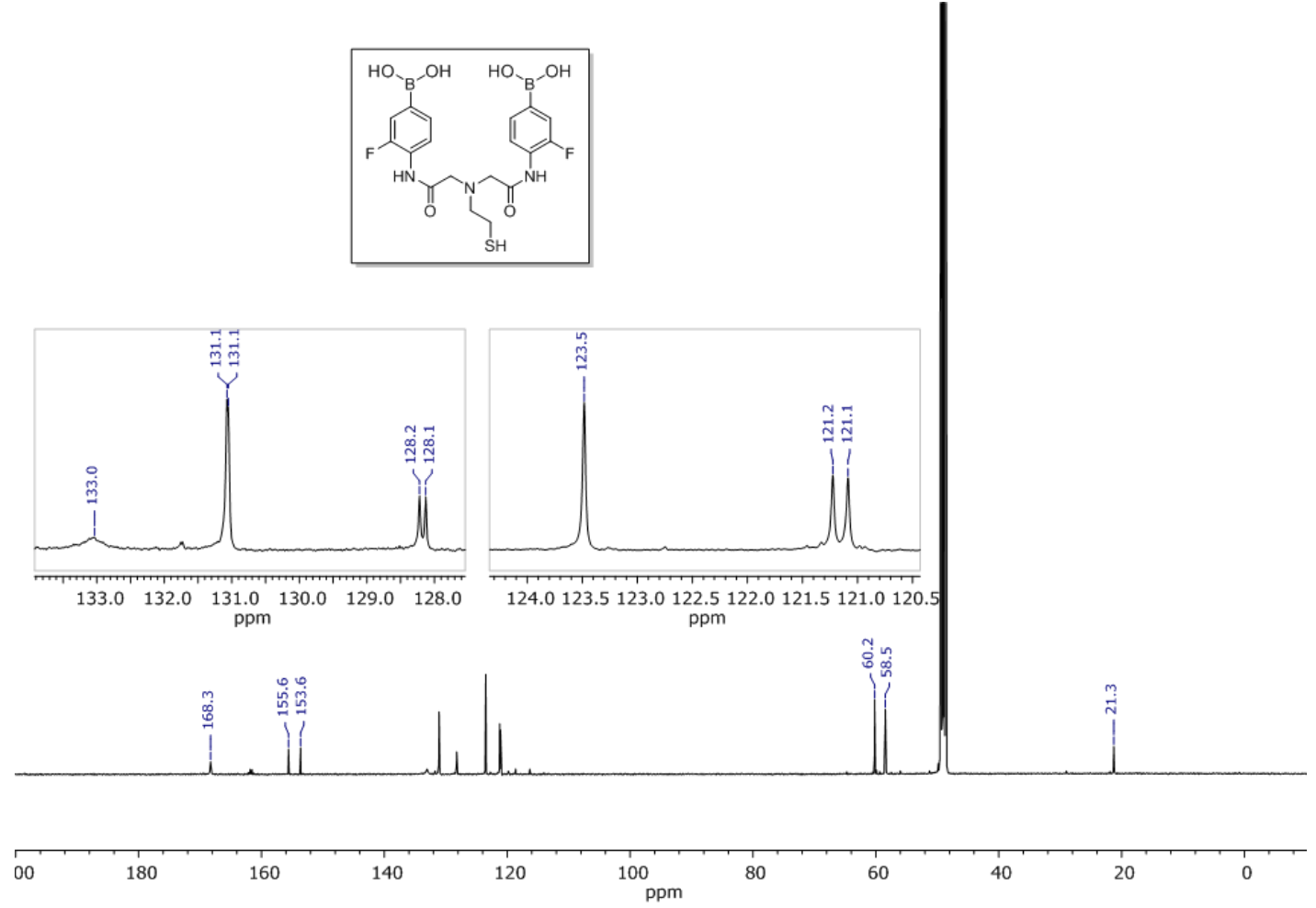

${ }^{13} \mathrm{C}$ NMR $\left(125 \mathrm{MHz}, \mathrm{CD}_{3} \mathrm{OD}+1 \mathrm{drop} \mathrm{D}_{2} \mathrm{O}\right)$ of compound $\mathbf{4 a}\left[{ }^{19} \mathrm{~F}\right.$-coupled] 

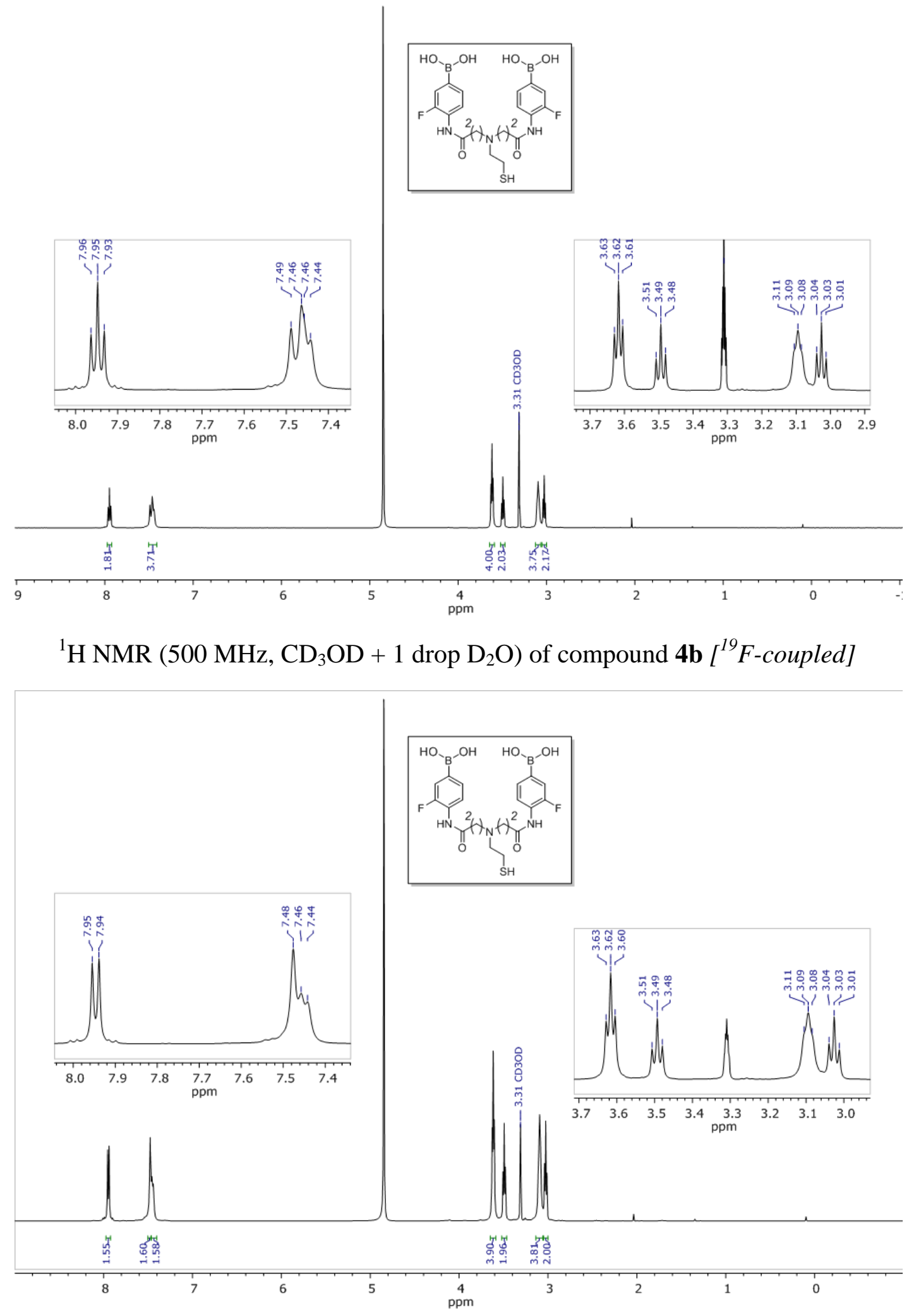

${ }^{1} \mathrm{H}$ NMR $\left(500 \mathrm{MHz}, \mathrm{CD}_{3} \mathrm{OD}+1\right.$ drop $\left.\mathrm{D}_{2} \mathrm{O}\right)$ of compound $4 \mathbf{b}\left[{ }^{19} \mathrm{~F}\right.$-decoupled] (shown for clarity) 


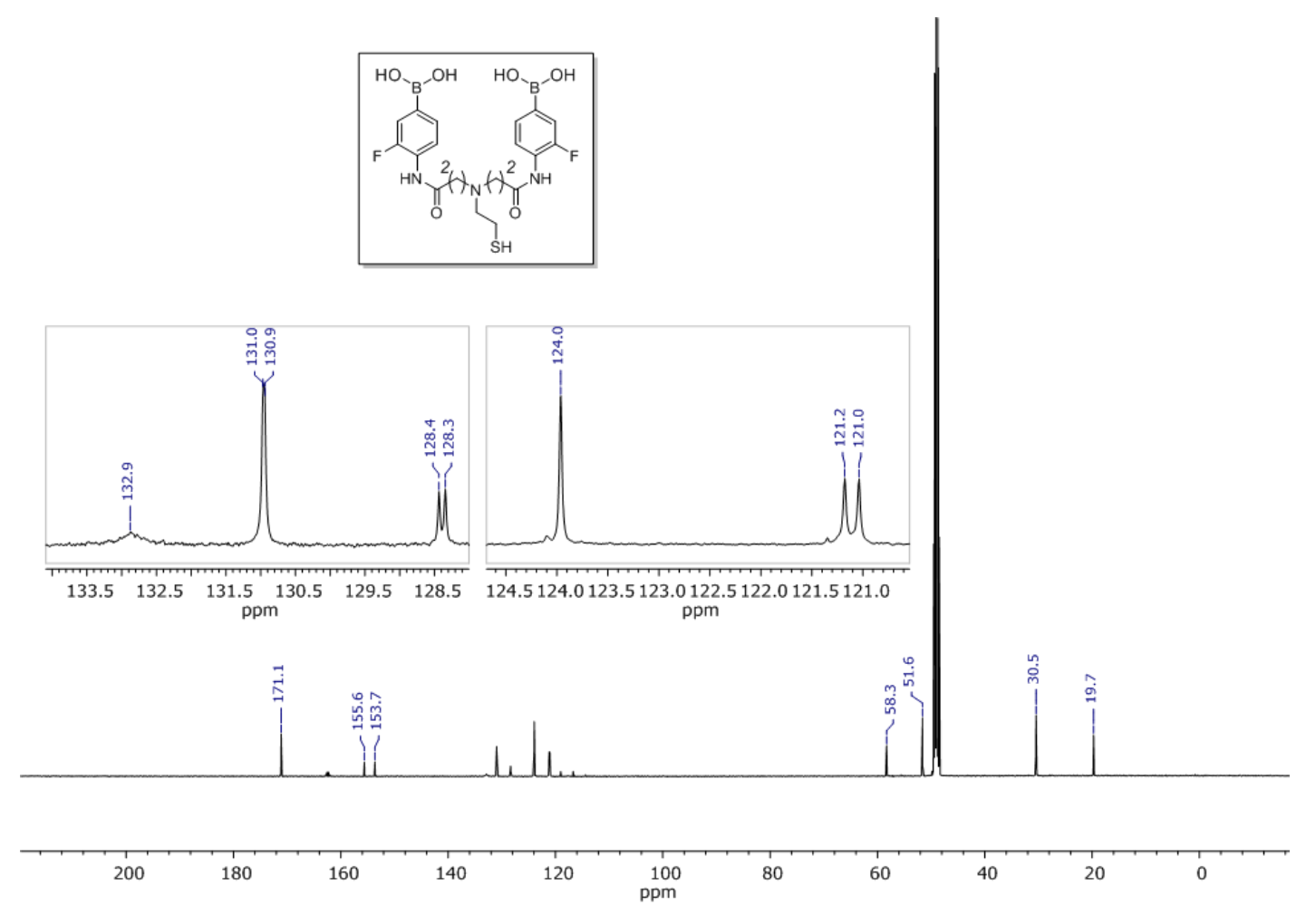

${ }^{13} \mathrm{C}$ NMR $\left(125 \mathrm{MHz}, \mathrm{CD}_{3} \mathrm{OD}+1\right.$ drop $\left.\mathrm{D}_{2} \mathrm{O}\right)$ of compound $4 \mathbf{b}\left[{ }^{19}\right.$ F-coupled] 


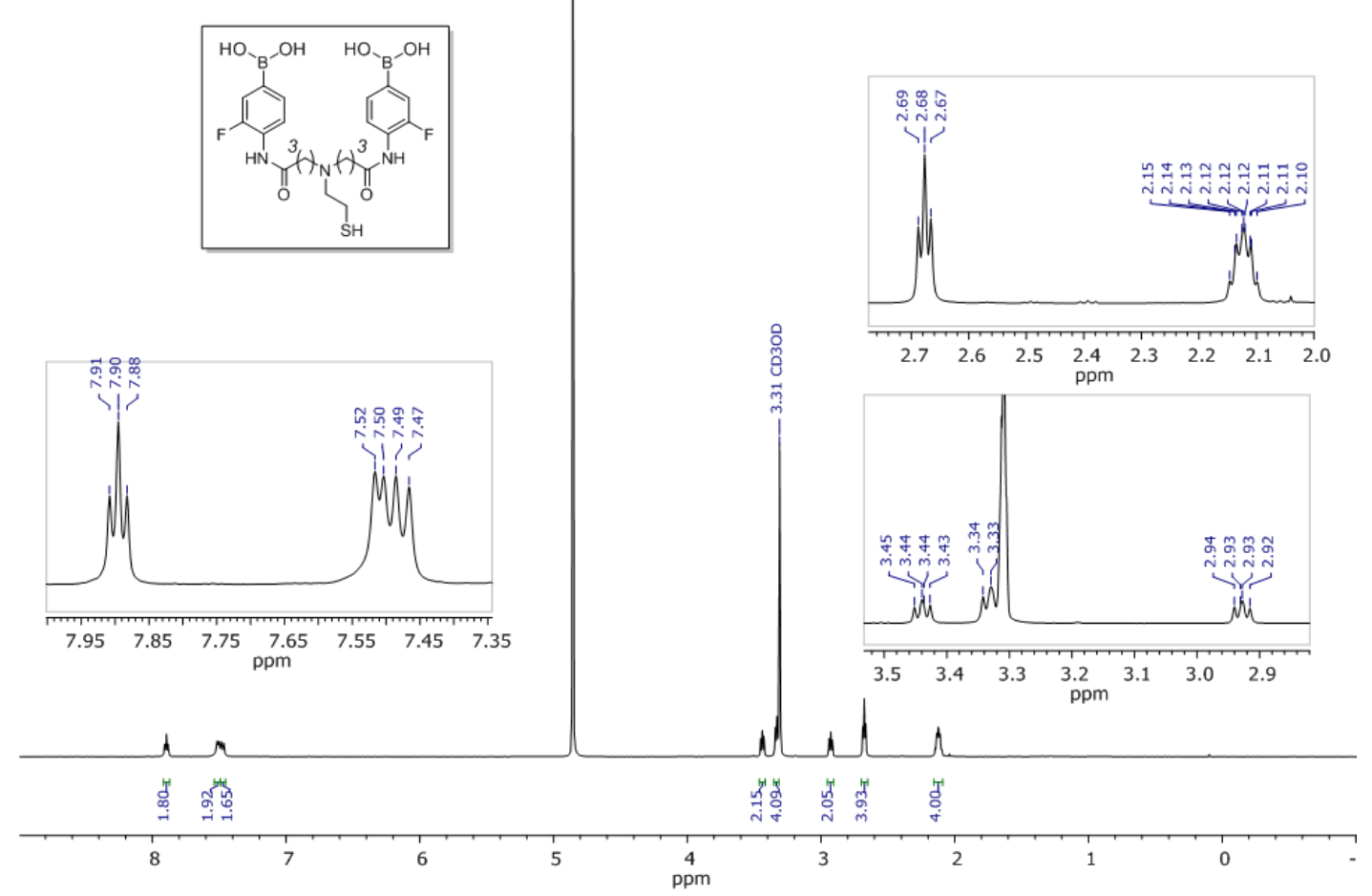

${ }^{1} \mathrm{H}$ NMR $\left(500 \mathrm{MHz}, \mathrm{CD}_{3} \mathrm{OD}+1\right.$ drop $\left.\mathrm{D}_{2} \mathrm{O}\right)$ of compound $4 \mathbf{c}\left[{ }^{19} F\right.$-coupled]
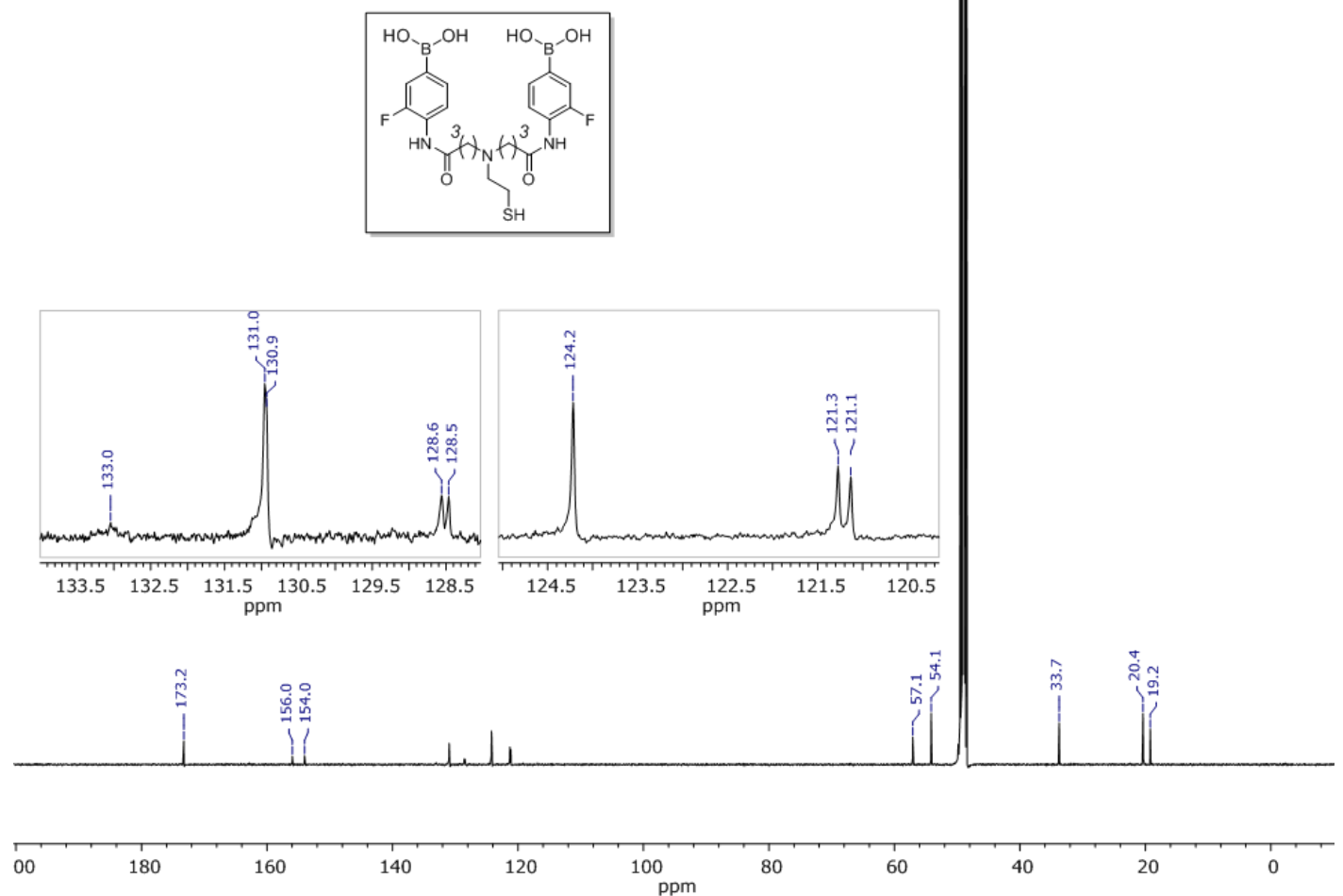

${ }^{13} \mathrm{C}$ NMR $\left(125 \mathrm{MHz}, \mathrm{CD}_{3} \mathrm{OD}+1\right.$ drop $\left.\mathrm{D}_{2} \mathrm{O}\right)$ of compound $4 \mathrm{c}\left[{ }^{19} F\right.$-coupled $]$ 


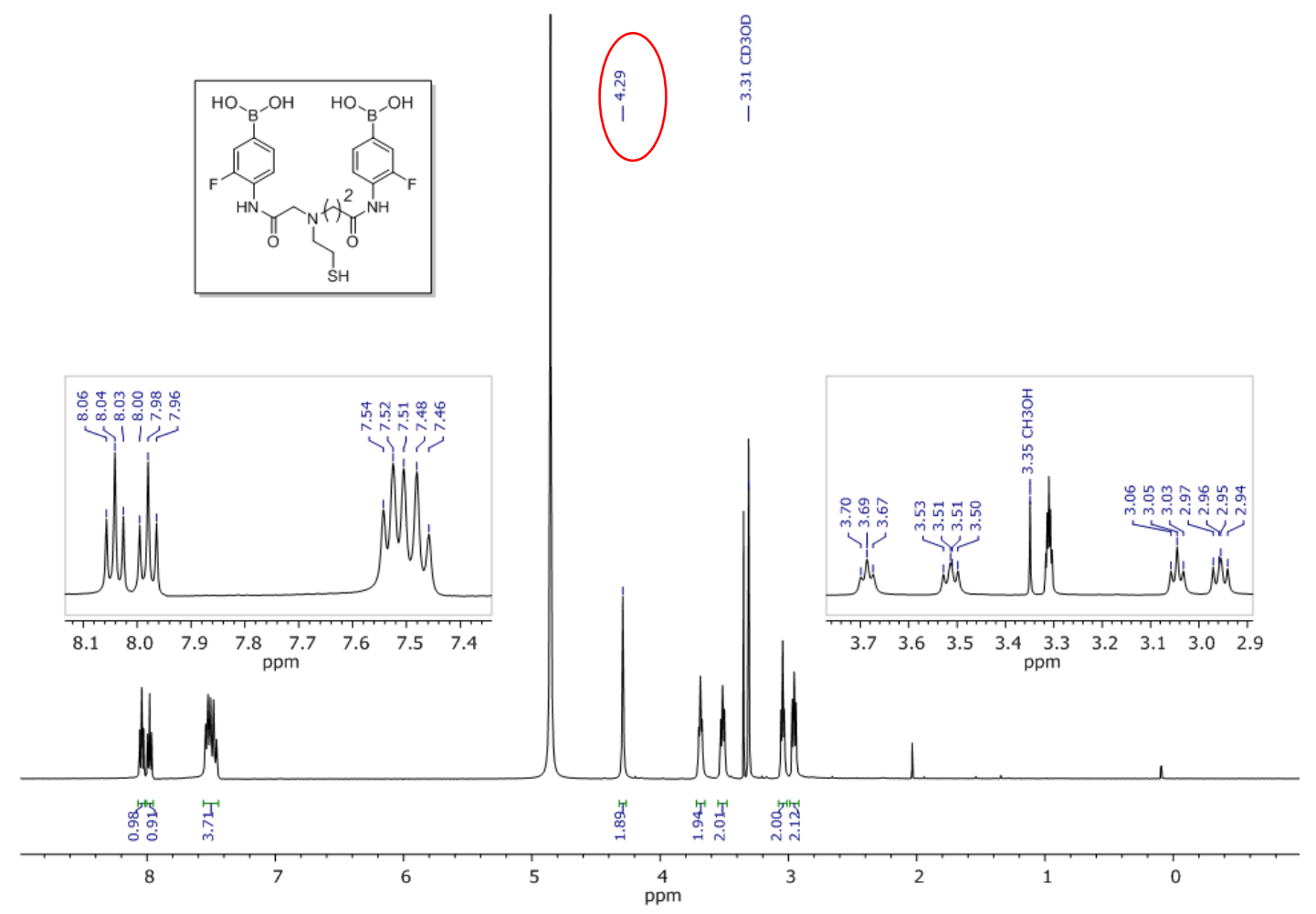

${ }^{1} \mathrm{H}$ NMR (500 MHz, $\mathrm{CD}_{3} \mathrm{OD}+1$ drop $\left.\mathrm{D}_{2} \mathrm{O}\right)$ of compound 9a $\left[{ }^{19}\right.$ F-coupled $]$
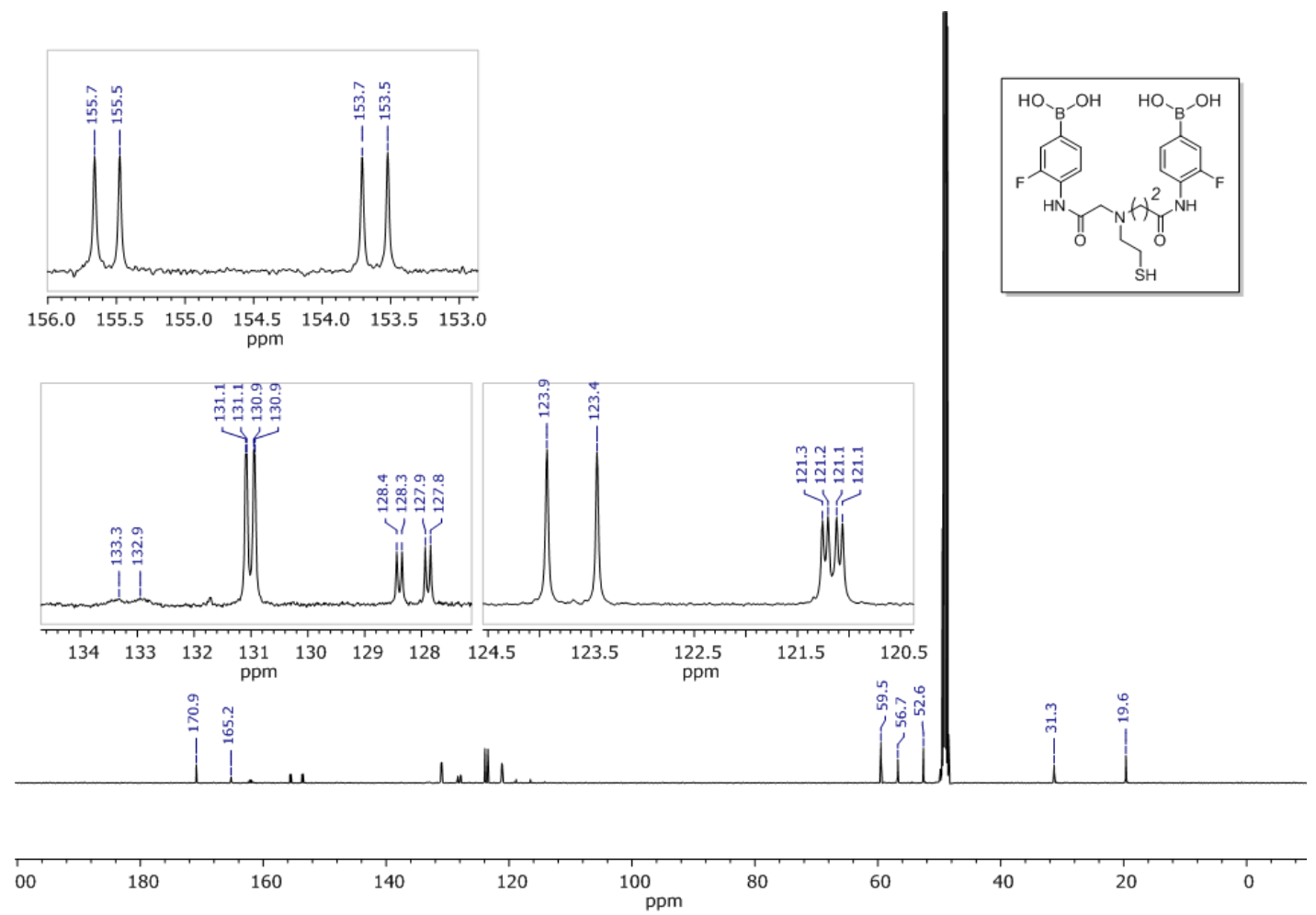

${ }^{13} \mathrm{C}$ NMR $\left(125 \mathrm{MHz}, \mathrm{CD}_{3} \mathrm{OD}+1 \operatorname{drop} \mathrm{D}_{2} \mathrm{O}\right)$ of compound 9a [ ${ }^{19}$ F-coupled] 

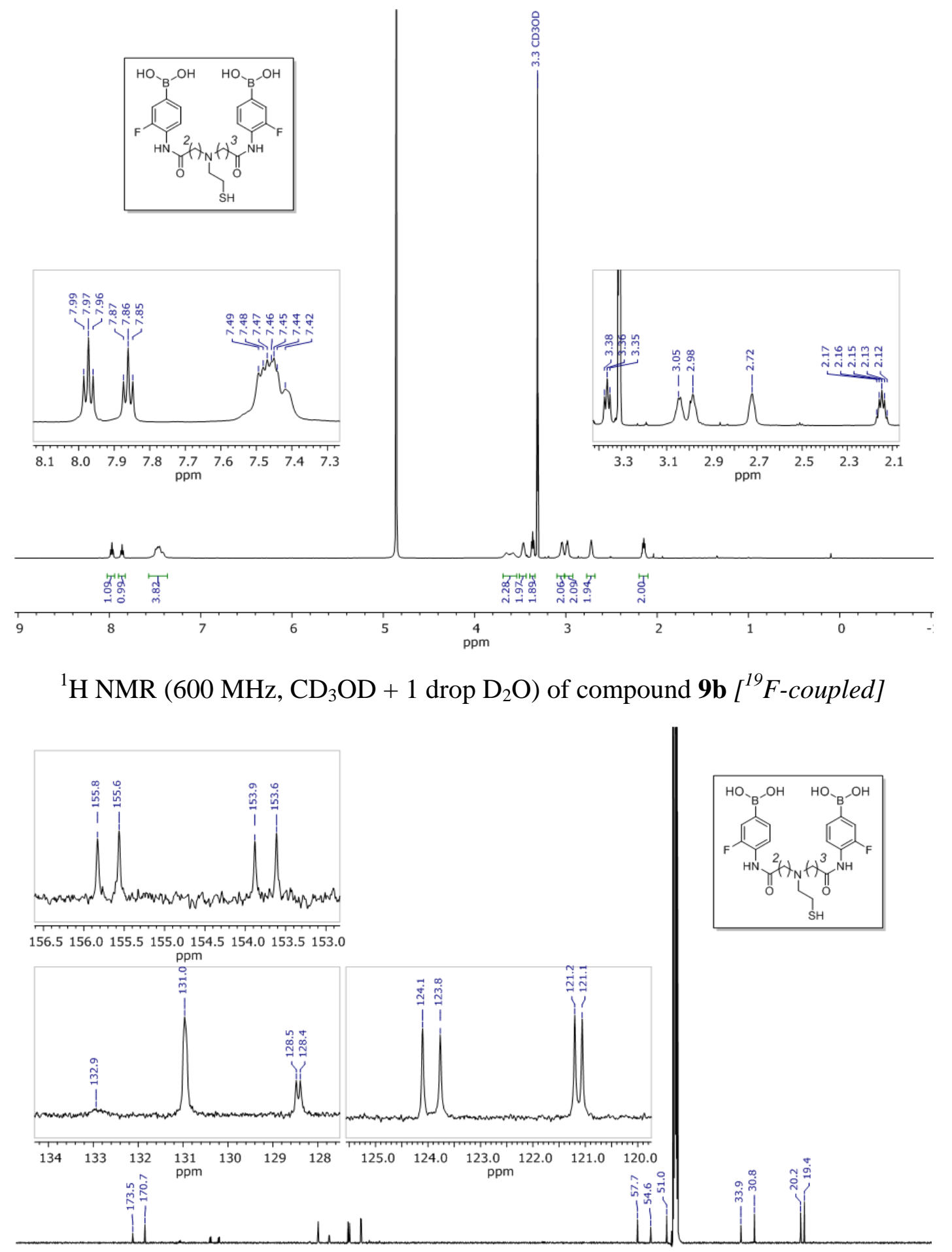

180
${ }^{13} \mathrm{C}$ NMR $\left(125 \mathrm{MHz}, \mathrm{CD}_{3} \mathrm{OD}+1\right.$ drop $\left.\mathrm{D}_{2} \mathrm{O}\right)$ of compound $9 \mathrm{~b}$ [ ${ }^{19}$ F-coupled]




\subsection{Normal Raman spectra of glucose and 4-amino-3-fluorophenylboronic acid: theory versus experiment}

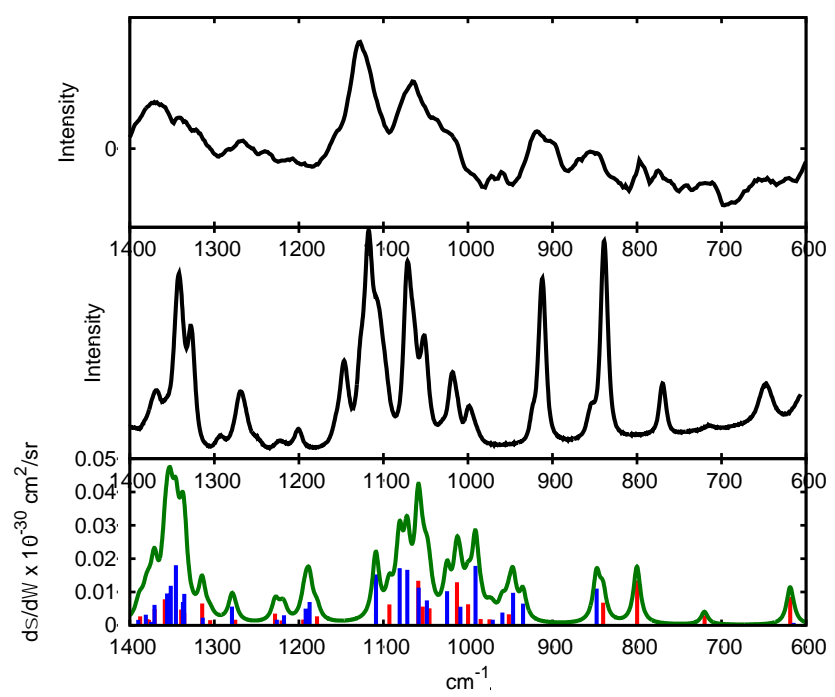

Figure S4. Normal Raman spectra of glucose. Top: normal Raman spectrum (NRS) of an aqueous 500 mM glucose solution. Middle: NRS of solid state glucose. $\left(\lambda_{\mathrm{ex}}=785 \mathrm{~nm} ; \mathrm{P}=17.7 \mathrm{~mW}\right)$ Bottom: NRS calculations showing the stick spectra and lorentzian broadened spectrum (green) of $\alpha$-glucopyranose (blue) and $\beta$-glucopyranose (red). The different anomeric structures of glucose can help explain distinct spectral features between $600 \mathrm{~cm}^{-1}$ and $900 \mathrm{~cm}^{-1}$.

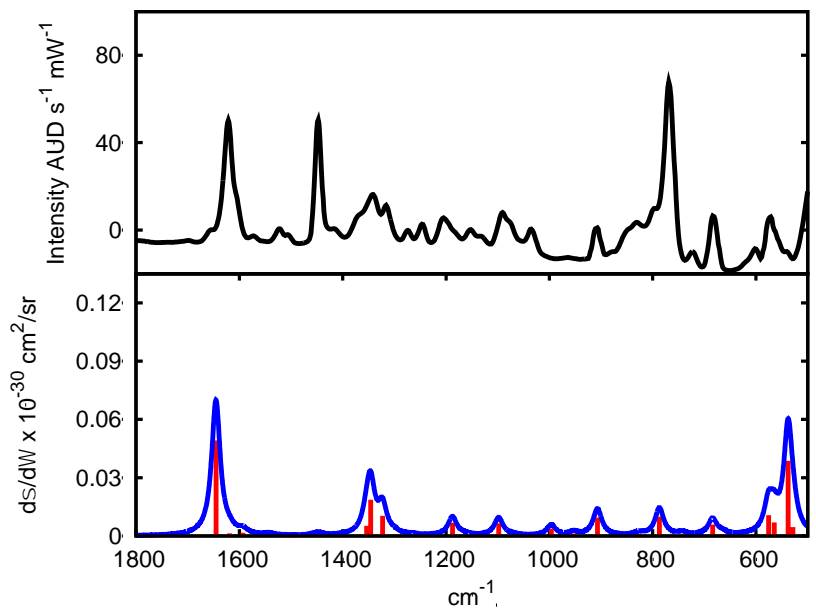

Figure S5. Normal Raman spectra of 4-amino-3-fluorophenylboronic acid. Top: NRS of 4-amino-3-fluorophenylboronic acid in aqueous solution $\left(\lambda_{\mathrm{ex}}=785 \mathrm{~nm} ; \mathrm{P}=17.7 \mathrm{~mW}\right)$. Bottom: Calculated NRS of 4-amino-3-fluorophenylboronic acid in a COSMO implicit solvent.

Table S1. Calculated and experimental vibrational modes and frequencies for solid and $500 \mathrm{mM}$ glucose.

\begin{tabular}{|c|c|c|c|}
\hline $\begin{array}{l}\text { Calculated } \\
\text { Glucose } \\
\left(\mathrm{cm}^{-1}\right)\end{array}$ & $\begin{array}{l}\text { Experimental } \\
\text { Glucose (solid) } \\
\left(\mathrm{cm}^{-1}\right)\end{array}$ & $\begin{array}{l}\text { Experimental } \\
\text { Glucose }(500 \mathrm{mM}) \\
\left(\mathrm{cm}^{-1}\right)\end{array}$ & Mode Characteristic and Species ( $\alpha$ or $\beta$ anomeric) \\
\hline 619 & 649 & 647 & $\mathrm{C}-\mathrm{O}-\mathrm{C}$ bending and ring distor- tion $(\alpha)$ \\
\hline \multirow[t]{2}{*}{721} & 712 (very weak) & 717 & $\mathrm{C}-\mathrm{C}-\mathrm{O}$ rocking and ring distor- tion $(\alpha)$ \\
\hline & 768 & 775 & $\mathrm{C} 6$ rocking and ring distortion through $\mathrm{C}-\mathrm{O}$ bending \\
\hline
\end{tabular}




\begin{tabular}{|c|c|c|c|}
\hline & & & $(\alpha)$ \\
\hline 799 & & 796 & $\begin{array}{l}\text { C6 rocking and ring distortion through } \mathrm{C}-\mathrm{O} \text { bending } \\
(\alpha)\end{array}$ \\
\hline 847 & 838 & 853 & $\begin{array}{l}\text { C6 rocking coupled to } \mathrm{C}-\mathrm{O}-\mathrm{C} \text { asymmetric } \\
\text { stretching and ring distortions }(\alpha \text { and } \beta)\end{array}$ \\
\hline 947 & 912 & 918 & Ring breathing mode $(\beta)$ \\
\hline 991 & 998 & & $\begin{array}{l}\text { Ring distortions via asymmetric stretching coupled } \\
\text { to the C6-O stretching }(\beta)\end{array}$ \\
\hline 1010 & 1018 & 1018 (shoulder) & $\begin{array}{l}\text { Asymmetric } \mathrm{C}-\mathrm{O}-\mathrm{C} \text { stretching and ring distortions } \\
(\beta)\end{array}$ \\
\hline 990 & 1051 & 1040 (shoulder) & $\begin{array}{l}\text { C6-O stretching coupled to C5-O- C1 symmetric } \\
\text { stretching }\end{array}$ \\
\hline 1013 & 1071 & 1065 & C5-O-C1 asymmetric stretching ( $\alpha)$ \\
\hline 1058 & 1118 & 1128 & $\begin{array}{l}\text { C2-C3-C4 symmetric stretching and ring distortions } \\
\text { ( } \alpha \text { and } \beta \text { ) }\end{array}$ \\
\hline 1108 & 1146 & 1153 (shoulder) & $\mathrm{C} 5-\mathrm{O}-\mathrm{C} 1$ bending coupled to $\mathrm{C} 1-\mathrm{OH}$ stretching \\
\hline 1190 & 1200 & not well resolved & H wagging and slight ring distor- tions ( $\alpha$ and $\beta)$ \\
\hline 1223 & 1225 (very weak) & 1238 & C2-O stretching \\
\hline 1279 & 1268 & 1267 & $\begin{array}{l}\text { Symmetric C-O-C stretching cou- pled to C-H } \\
\text { wagging }(\alpha \text { and } \beta)\end{array}$ \\
\hline 1337 & 1327 & 1341 & molecule-wide $\mathrm{C}-\mathrm{O}$ stretching ( $\alpha$ and $\beta$ ) \\
\hline 1353 & 1341 & 1369 & $\begin{array}{l}\text { molecule-wide } \mathrm{C}-\mathrm{C} \text { stretching coupled to } \mathrm{C}-\mathrm{H} \\
\text { stretching }(\alpha \text { and } \beta)\end{array}$ \\
\hline 1370 & 1368 & 1393 (shoulder) & C5-C6 stretching coupled to O-H bending ( $\alpha$ and $\beta$ ) \\
\hline 1442 & & 1462 & C6 bending ( $\alpha$ and $\beta$ ) \\
\hline
\end{tabular}


Table S2. Calculated and experimental vibrational modes and frequencies for solid and aqueous fructose.

\begin{tabular}{|c|c|c|c|}
\hline $\begin{array}{l}\text { Calculated } \\
\text { Fructose }\left(\mathrm{cm}^{-1}\right)\end{array}$ & $\begin{array}{l}\text { Experimental } \\
\text { Fructose } \\
(\mathrm{solid}) \\
\left(\mathrm{cm}^{-1}\right)\end{array}$ & $\begin{array}{l}\text { Experimental Fructose } \\
\text { (aqueous) } \\
\left(\mathrm{cm}^{-1}\right)\end{array}$ & Mode Characteristic \\
\hline 518 & 527 & 522 & Ring distortions via C2 bending ( $\alpha$ and $\beta$ ) \\
\hline 567 & 593 & 599 (shoulder) & $\mathrm{C} 2$ and $\mathrm{C} 4$ bending $(\alpha)$ \\
\hline 581 & 627 & 689 & C5-C6 stretching $(\beta)$ \\
\hline 691 & & 704 & $\begin{array}{l}\mathrm{C} 2-\mathrm{O}-\mathrm{C} 4 \text { symmetric stretching coupled to } \mathrm{C} 6 \text { bending }(\alpha \\
\text { and } \beta)\end{array}$ \\
\hline 803 & 816 & 821 & C2-O-C4 symmetric stretching ( $\alpha$ and $\beta$ ) \\
\hline 867 & 872 & 867 & C4 bending coupled to C5-O stretching ( $\alpha$ ) \\
\hline 897 & 924 & 918 & C2-O-C4 symmetric stretching ( $\alpha$ and $\beta$ ) \\
\hline 972 & 977 & 979 & C3 symmetric stretching $(\alpha$ and $\beta$ ) \\
\hline 994 & 1045 & 1064 (shoulder) & $\mathrm{C}-\mathrm{OH}$ stretching $(\alpha)$ \\
\hline 1022 & 1059 & 1064 (shoulder) & Ring distortions via $C-C$ stretching $(\alpha$ and $\beta$ ) \\
\hline 1045 & 1080 & 1083 & $\begin{array}{l}\text { Ring breathing coupled to } \mathrm{C6}-\mathrm{OH} \text { stretching ( } \alpha \text { and } \\
\text { B) }\end{array}$ \\
\hline 1144 & 1142 & 1149 & $\begin{array}{l}\text { Ring distortions via O-C4-C3 asymmetric stretching } \\
(\alpha)\end{array}$ \\
\hline 1168 & 1177 & 1179 & Ring distortions via C-O-C bend- ing $(\beta)$ \\
\hline 1204 & 1249 & & Ring distortions via C1-O stretching ( $\alpha$ and $\beta$ ) \\
\hline 1241 & 1264 & 1264 & Ring distortions via $\mathrm{C} 1$ and $\mathrm{C} 4$ bending $(\alpha$ and $\beta)$ \\
\hline 1325 & 1340 & no well defined feature & Ring distortions via $\mathrm{C}-\mathrm{C}$ stretching $(\alpha$ and $\beta$ ) \\
\hline 1381 & 1399 & no well defined feature & Ring distortions via $\mathrm{C}-\mathrm{O}$ stretching $(\alpha$ and $\beta)$ \\
\hline 1480 & 1455 & & $\mathrm{C} 1$ and $\mathrm{C} 6$ bending $(\alpha$ and $\beta)$ \\
\hline 1484 & 1471 & 1459 & C1 and $\mathrm{C} 6$ bending $(\alpha$ and $\beta)$ \\
\hline
\end{tabular}




\subsection{Normal Raman spectra of glucose and fructose compared to the SER spectra of glucose and fructose bound to 4-amino-3-fluorophenylboronic acid}

A

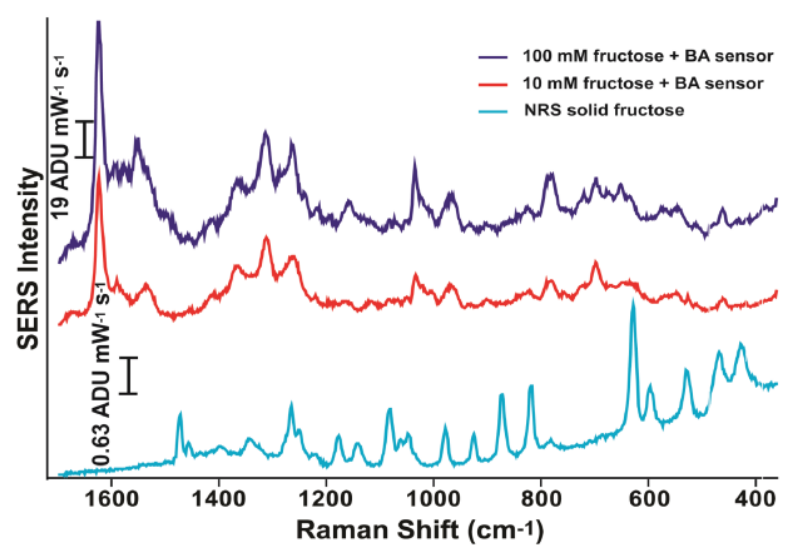

B

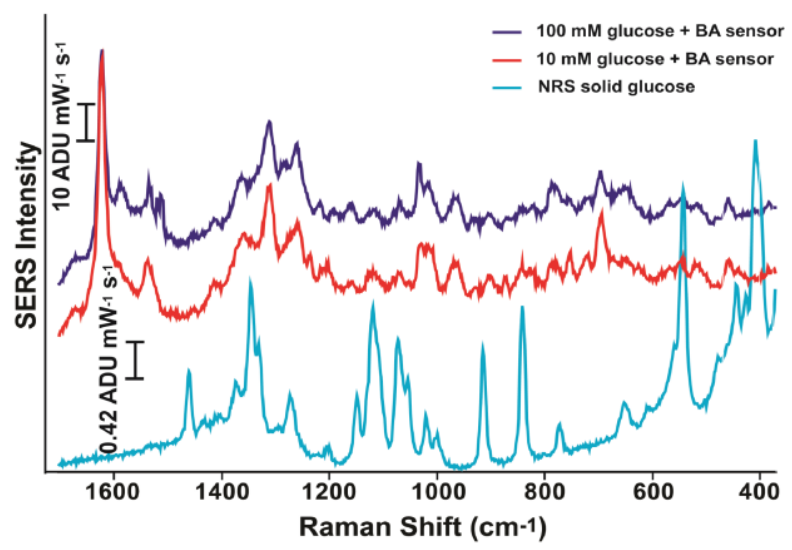

Figure S6. SERS spectra of $100 \mathrm{mM}$ (purple) and $10 \mathrm{mM}$ (red) sugar concentration bound to 4-amino-3-fluorophenylboronic acid on a AuFON compared to the normal Raman spectrum of the solid sugar (blue). SERS spectra excited at $\lambda_{\mathrm{ex}}=785 \mathrm{~nm}, \mathrm{t}=30 \mathrm{sec}$, $\mathrm{P}=713 \mu \mathrm{W}$; normal Raman spectra at at $\lambda_{\mathrm{ex}}=785 \mathrm{~nm}, \mathrm{t}=30 \mathrm{sec}, \mathrm{P}=17.7 \mathrm{~mW}$. The difference in intensity between the NR and SER spectra reflects the number density of the bulk sugars $\left(\sim 10^{20}\right.$ molecules. $\left.\mathrm{cm}^{-3}\right)$ versus the surface number density of the boronic acid-sugar complex $\left(\sim 10^{14}\right.$ molecules. $\left.\mathrm{cm}^{-2}\right)$.

\section{References}

1. Daly, T.A. ; Almeida, P.F.; Regen, S.L. J. Am. Chem. Soc. 2012, 134, 17245-17252

2. Zugates, G.T.; Anderson, D.G.; Little, S.R.; Lawhorn, I.E.B.; Langer, R. J. Am. Chem. Soc. 2006, 128, 12726-12734

3. Sharma, G.V.M.; Reddy, C. G.; Radha Krishna, P. J. Org. Chem. 2003, 68, 4574-4575.

4. Bruns, S.; Sinnwell, V.; Voss, J. Magn. Reson. Chem. 2003, 41, 269-272. 